\title{
Do Stock Prices Move too Much to be Justified by Changes in Dividends? \\ Evidence from Real Estate Investment Trusts *
}

\author{
Tobias Mühlhofer ${ }^{\dagger}$ \\ Andrey D. Ukhov $\ddagger$ \\ Indiana University \\ Indiana University
}

August 15, 2009

\begin{abstract}
A central issue in asset pricing is whether asset prices move too much in relation to cash flows. We take advantage of the existence of two parallel markets for a set of cash flows to show that better measurement of cash flows can dramatically improve the performance of a dynamic dividend discount model. We apply the model to returns on Real Estate Investment Trusts (REITs) and REIT dividends. We use a unique data set of directly held commercial real estate and augment information in REIT dividends with information from cash flows from this parallel market. The addition of this information leads to a significant improvement in the performance of a traditional dividend discount model. First, when REIT dividends are supplemented with direct property dividends, innovations in cash flows and economic news explain approximately $24 \%$ of REIT return variation. This is higher than the approximately one-fifth of variation explained in the stock market as reported in the classic study by Cutler, Poterba and Summers (1989). Second, we apply a dividend discount model to REITs, using out-of-sample estimation, unlike previous literature. When only information from REIT dividends is used, the model performs somewhat better than was previously found for the stock market (Campbell and Shiller (1988b)), which is congruous with the nature of REITs and the information content of their dividends. The results, however, further improve dramatically when information from direct property cash flows is added to the model. These findings suggest that the performance of dividend pricing models improves greatly with better measurement of cash flows, and thus contribute to the resolution of the excess volatility puzzle.
\end{abstract}

Keywords: Dividend Pricing Models, Excess Volatility, Cash Flows, Vector Autoregression, Real Estate Investment Trusts.

JEL Classifications: G12, G14, G17, G29

\footnotetext{
${ }^{*}$ We are thankful to Jeff Fisher for helpful discussion and for providing the direct property data, as well as to Charles Trzcinka, to conference participants and our discussion panel at RERI, to seminar participants at Indiana University, and to our RERI mentors Michael Grupe and Youguo Liang for helpful comments. We gratefully acknowledge funding from the Real Estate Research Institute for this project.

${ }^{\dagger}$ Tobias Mühlhofer, Kelley School of Business, Indiana University, 1309 East 10th Street, Bloomington, IN 47405. Telephone: 812-855-9270, Fax: 812-855-5875, E-mail: tmuhlhof@indiana.edu, Website: http://tobias.muhlhofer.com, where this paper is available for download.

${ }^{\ddagger}$ Andrey D. Ukhov, Kelley School of Business, Indiana University, 1309 East 10th Street, Bloomington, IN 47405. Telephone: 812-855-2698, Fax: 812-855-5875. E-mail: aukhov@indiana.edu
} 


\title{
Do Stock Prices Move too Much to be Justified by Changes in Dividends? \\ Evidence from Real Estate Investment Trusts *
}

\author{
August 15, 2009
}

\begin{abstract}
A central issue in asset pricing is whether asset prices move too much in relation to cash flows. We take advantage of the existence of two parallel markets for a set of cash flows to show that better measurement of cash flows can dramatically improve the performance of a dynamic dividend discount model. We apply the model to returns on Real Estate Investment Trusts (REITs) and REIT dividends. We use a unique data set of directly held commercial real estate and augment information in REIT dividends with information from cash flows from this parallel market. The addition of this information leads to a significant improvement in the performance of a traditional dividend discount model. First, when REIT dividends are supplemented with direct property dividends, innovations in cash flows and economic news explain approximately $24 \%$ of REIT return variation. This is higher than the approximately one-fifth of variation explained in the stock market as reported in the classic study by Cutler, Poterba and Summers (1989). Second, we apply a dividend discount model to REITs, using out-of-sample estimation, unlike previous literature. When only information from REIT dividends is used, the model performs somewhat better than was previously found for the stock market (Campbell and Shiller (1988b)), which is congruous with the nature of REITs and the information content of their dividends. The results, however, further improve dramatically when information from direct property cash flows is added to the model. These findings suggest that the performance of dividend pricing models improves greatly with better measurement of cash flows, and thus contribute to the resolution of the excess volatility puzzle.
\end{abstract}

Keywords: Dividend Pricing Models, Excess Volatility, Cash Flows, Vector Autoregression, Real Estate Investment Trusts.

JEL Classifications: G12, G14, G17, G29

${ }^{*}$ We are thankful to Jeff Fisher for helpful discussion and for providing the direct property data, as well as to Charles Trzcinka, to conference participants and our discussion panel at RERI, to seminar participants at Indiana University, and to our RERI mentors Michael Grupe and Youguo Liang for helpful comments. We gratefully acknowledge funding from the Real Estate Research Institute for this project. 


\section{Introduction}

Sources of variability in asset returns are at the center of the debate in the empirical asset pricing literature. Every empirical model of variation in asset returns tells a story about the exogenous shocks that are ultimately responsible for changes in the prices of risky assets. The characterization of these ultimate sources of variability is of fundamental interest to financial economists in order to better understand what drives asset returns.

An important part of this literature works within the economic framework of a Net Present Value model (see for example Shiller (1981), Campbell and Shiller (1988a,b)). This approach attempts to firstly draw a broad distinction between attributing variability in asset prices to either changes in information related to cash flows, or changes in information related to the discount factor. The latter component - the discount factor - then yields itself to further distinctions between changes in the risk-free interest rate and changes in the market's required risk premium. One of the empirical problems associated with this approach is that it is often difficult to find variables that accurately reflect changes in these fundamental sources of variability; doing so effectively is necessary to correctly attribute price variability to a respective source.

This study takes interest in the empirical challenge of appropriately capturing changes in cash flows. While basic economic rationale posits that for equity securities, actual payments to investors (i.e. primarily dividends) should be the relevant metric for the cash flows associated with the security, empirical tests have failed to show that changes in information related to dividends hold the expected level of importance in determining asset returns. In other words, the literature has found that asset prices are more volatile than can be explained by changes in dividend information, and this phenomenon has come to be known as the excess volatility puzzle. This apparent inconsistency has often been attributed to the idea that dividends (and other cash flow measures such as earnings with which such models have been refined) are not accurate representations for the stream of cash flows which investors perceive underlies the equity securities in question, because they can be smoothed, managed, or otherwise manipulated by the respective firm, and firm management has incentive to do this. Thus, since the cash flow proxy used lacks volatility in itself, tests using such proxies are pre-destined to obtain an excess-volatility result. If it were possible for 
an econometrician to observe the true (un-smoothed) cash flow information that the underlying market contains, it would be possible to make better attributions of sources of variation.

We contribute to the literature by examining the improvements to the performance of dynamic Net-Present-Value models that can be achieved by improving the accuracy of the cash-flowinformation proxy that is used. We find that using a more accurate cash flow proxy, vastly improves the predictive ability of such models. The improved performance of our model comes despite the fact that, unlike previous literature, we conduct all estimation out of sample and thus avoid lookahead bias. We are able to construct such cash flow proxies by taking advantage of the unique features of Real Estate Investment Trusts (REITs) as a natural experiment.

REITs present at least two advantages, when compared to ordinary equity securities. Firstly, due to the fact that REITs derive their cash flows from the operation of commercial property, these firms should offer a higher level of transparency than other firms, since commercial real estate (held and operated by REITs) is more straightforward to price than more complex assets held by ordinary companies (e.g. an assembly line for rivets). Thus, there is less incentive and necessity for firm management to manage traditional cash flow measures in order to signal information about the firm to the market, as the informational asymmetry is lower. ${ }^{1}$ Secondly, it is possible for a REIT investor, as well as for an econometrician, to directly observe returns for commercial property from the primary (or direct) real estate market, in which REITs trade, but which of course has its own readily observable dynamics, since REITs only constitute a part of this asset market. Thus, an investor can supplement his or her information derived from firm-based cash flow information with cash flow information from the direct property market. At the same time, we as econometricians can readily observe this information, and therefore are better able to understand the investor's information set as it pertains to cash flows. This fuller view of the investor's cash flow information, in turn, gives us the ability to better model the cash flow-related component of asset price variability and thus to make a better determination of how important a role this source of variation plays in determining overall asset returns. In this study, we take two different approaches toward this task.

\footnotetext{
${ }^{1}$ In addition to this, REITs are mandated to pay out at least $90 \%$ of their taxable income as dividends. While this removes some discretion from dividend policy, it is a less binding constraint than it seems, due to the high amounts of depreciation which REITs can claim. See for example Kallberg, Liu and Srinivasan (2003). Section 3 presents further elaboration of this issue.
} 
We begin by studying the connection between asset returns and dividends in our data set first by using a less structured approach. We study returns in three asset markets-stocks, REITs, and the direct property market-to identify what fraction of asset returns can be attributed to innovations in dividends and other explanatory variables. We use a comprehensive real estate data set that contains return and cash flow information on directly held institutional-quality real estate. The data has quarterly observations for the period from 1978 through 2007 . While benefiting from the ability to better measure cash flows in this setting, we are paying the price because this is a shorter time span than commonly examined in the studies based on stock market data. To investigate whether dividend innovations contain information that explains variation in asset returns in our data, we employ an approach similar to the classic study by Cutler, Poterba and Summers (1989) who study the impact of economic news on stock prices.

We define a set of state variables that can be a source of variation in returns. The state variables are chosen to measure cash flows, economic conditions, risk, and the risk-free discount rate. Since we study three asset markets, we work with returns and dividends for stocks, REITs, and direct properties. Our state variables are logarithm of real dividend payments, long-term interest rate, short-term interest rate, volatility as a measure of risk, logarithm of industrial production, and the logarithm of real money supply. We estimate a Vector Autoregression (VAR) system that includes all of the state variables. Residuals from the VAR equations represent the news (innovations) for the state variables. An important feature of this methodology is that because the VAR system takes into account the joint dynamics of the variables in the system, the residuals represent innovations after the mutual impact of the variables have been accounted for. We then regress real returns on the innovations in the state variables. The $R^{2}$ for this regression measures the fraction of the return variation that can be explained by innovations in the state variables.

The analysis of stock returns (using stock dividends as a state variable) establishes the benchmark case. For the stock market returns, we find that innovations in state variables explain approximately $22 \%$ of variation in returns. This number is somewhat higher than the approximately $19 \%$ reported by Cutler, Poterba and Summers (1989) who use similar state variables but work with more observations (they use monthly series for 1926-1985). Our results for REITs are sim- 
ilar. When we supplement REIT dividends with direct property dividends as state variables, we find that state variable innovations explain approximately $24 \%$ of return variation. For the direct property market, where a good measure of risk is not available, the explanatory power is somewhat lower. For all three markets we do find that innovations in dividends are a central component for explaining return variation. In a challenging environment of relatively short time series, we are able to establish that dividend innovations are important in explaining real estate asset returns. Once we establish that dividend innovations are a crucial source of variation in asset returns in our data set, we proceed with more structured tests of the dividend pricing model.

Our second approach relies on the literature on dividend pricing models, influentially shaped in studies such as Campbell and Shiller (1988a,b). In this methodology, a structural model is imposed on asset price dynamics, which is based on an empirically estimable version of a dynamic (i.e. time-varying) Net Present Value Model. In this context, asset price variability is associated with variations in current dividends, expected discount factors, and expected dividend growth rates. A useful approach here consists of modeling prices conditional on current dividends, in order to better gauge the dynamics of market expectations. Thus, this approach consists of modeling the dividend yield (the ratio of current dividend over current price), and in line with this, these models are called dividend ratio models. The general idea in this line of literature is to model the dividend yield based on state variables relating to cash flow- and interest-rate information, and testing what percentage of the overall variation in dividend yields this information explains.

Despite its economic justification, results of tests of the dividend pricing model through this approach in past literature have been rather negative. Campbell and Shiller (1988a,b), for example, assume a constant discount factor and, by examining the dynamics of the dividend yield, reject the dividend pricing model, in that they find stock prices to be too volatile to be explained purely by the dynamics of dividends (excess volatility). Cochrane (1992, 2001, 2007) as well as Campbell and Ammer (1993), for example, examine the dividend yield directly, and determine that almost all the variation in this measure is driven by changes in the discount rate.

One criticism of this approach lies in the fact that dividends do not constitute the only distribution that a firm makes. Ackert and Smith (1993), for example, test a dividend pricing model 
using not only dividends, but also other distributions a firm makes (such as share repurchases), with better results. Another criticism of this approach has been that dividends are smoothed (see for example Lintner (1956)), and that therefore the dynamics of dividends do not accurately reflect the dynamics of the perceived cash flows which investors feel that a financial asset entitles them to. In order to remedy this, dividend-pricing type models have been augmented by the inclusion of earnings (for example Campbell and Shiller (1988b)), which is generally found to be an important variable, but still does not lead to an outcome in which dividend yields (and therefore ultimately the dynamics of asset prices) are driven in large part by cash flow-related components. Some of this effect has been attributed to the phenomenon known as earnings smoothing, or more generally earnings management or manipulation, a similar effect to dividend smoothing, in that it leads to an outcome in which even earnings do not proxy for the dynamics of cash flows underlying a security that investors perceive.

We first use REIT dividends alone as a cash flow proxy. As stated above, REIT dividends should contain more information and less smoothing than the dividends of ordinary equities. In doing this, we confirm the findings of Kallberg, Liu and Srinivasan (2003), but out of sample. Kallberg et al. (2003) test the dividend-yield models of Campbell and Shiller (1988a) on a sample of REITs, using not just dividends but all distributions, and find that the dividend pricing model is not rejected for REITs. They also rerun these tests on the S\&P 500 Index, where they do reject the dividend pricing model.

This study's most important contribution in this respect, however, lies in exploiting the relationship between the two parallel asset markets, by adding direct-property returns data (instead of earnings data, like for example in Campbell and Shiller (1988b)) to the cash flow information set on which a dividend pricing model is tested. Since the data we use for this purpose comes from properties held by entities which are not continuously publicly traded, and this data is collected privately and only published in aggregate by its provider, it seems that the participants who provide this data have little to no incentive for manipulation or management thereof, and so this data should provide market participants, as well as econometricians, with reliable information on the true cash flows 
produced by the commercial property market. ${ }^{2}$ In this study we demonstrate the improvement that this information content gives to the traditional dividend pricing models. By augmenting the cash flow-related information, we should also come closer to isolating that component of dividend yields which is driven by changes in the discount factor.

To offer preliminary evidence in favor of the hypothesis that direct-property cash flow information is useful in determining REIT prices, we construct a NOI yield variable, which is constructed as the ratio of direct-property Net Operating Income (NOI) divided by REIT prices. Conceptually, this resembles a REIT dividend yield, except that cash flows are represented by income from a large commercial direct-property portfolio. We run a basic regression of changes in the logarithm of this variable on log-changes in the risk-free rate, with the idea that if this variable does indeed represent a type of dividend yield, a part of its variation should be explained by changes in the risk free rate, just like actual dividend yields. We find that this is the case, which offers encouraging preliminary evidence for the usefulness of this cash flow measure in modeling dividend prices.

We then proceed to estimate a Vector Autoregression (VAR) system, in the spirit of Campbell and Shiller $(1988 \mathrm{~b}, \mathrm{a})$. This approach consists of using a vector of state variables containing the dividend yield as well as variables pertaining to certain sources of variation, in a VAR procedure, in order to construct predicted dividend yields based on these variables. Economically, these predicted dividend yields proxy for that component of the variation in dividend yields which relates to the variables in this state vector. It is then possible to draw statistical comparisons between the predicted dividend yields and the actual observed ex-post dividend yields, in order to determine how much of the overall variation in dividend yields is captured by the state variables included. The figures we produce in order to make this comparison are the ratio of the standard deviation of the predicted dividend yields from each VAR specification over the standard deviation of the observed dividend yields, as well as the correlation between the two series of dividend yields. The idea is that if this ratio is high, while at the same time the two series of dividend yields are highly correlated,

\footnotetext{
${ }^{2}$ Besides the data we use, there exist a number of reliable data sources on commercial property returns that are available for purchase, as well as through private channels. While it may not be the case that REIT analysts or informed REIT investors have access to the exact same data source as we use, it should be very reasonable to assume that such agents have access to some source of reliable direct information about property returns, which our direct property data proxies for.
} 
the predicted dividend yields constructed solely from a particular information set closely mirror those actually applied to asset prices in the market, and therefore this set of variables has a large influence on the overall variation in dividend yields and ultimately asset prices. It is important to note that once again that our empirical approach differs from that of Campbell and Shiller (1988a,b) and Kallberg et al. (2003), in that while these studies estimate their VARs over their entire data sample and compute the predicted dividend yields just as fitted values from the VAR estimation, we conduct our VAR estimations on which we base our predictions using a 40-quarter rolling window, and constructing the prediction out of sample. This should more cleanly capture true information content available to market participants at a particular point in time, while also allowing for the relationships described within this VAR system to be time-varying.

Using quarterly data from 1980 through 2007, we begin by estimating a benchmark VAR system, consisting of the logs of REIT dividend yields, the logs of REIT dividend growth rates, and the logs of the long-term interest rate. We find that with two lags, where this system seems to generate the best forecast dividend yields, the ratio of the standard deviations of the predicted over the actual dividend yield is .7108 , while the correlation between the two yield series is $.4528 .^{3}$ When we add the logs of NOI yields (quarterly net operating income to our direct property portfolio, divided by end-of-quarter REIT prices) to this system, the ratio of the standard deviations increases to .9563, while the correlation coefficient increases to .6847. These numbers increase further to .9813 and .7323, respectively, when we add the logs of quarterly direct-property NOI growth to this system and do not decrease much (.9291 and .7313), if we exclude the logs of quarterly REIT dividend growth and only use the logs of dividend yield, NOI yield, NOI growth, and the long-term rate. This presents strong evidence that our direct property cash flow variables constitute important information for the pricing of REITs, and more generally suggests that, if cash flow information is more fully captured empirically, such information does constitute a very important component in the determination of asset prices, yielding general support to dividend pricing models.

We then estimate OLS regressions with the log-difference between the observed dividend yields

\footnotetext{
${ }^{3}$ This ratio of standard deviations is close to that found in Kallberg et al. (2003), who use similar variables in their VAR setup, while Campbell and Shiller (1988a) in the model specification that resembles ours but uses regular stocks, find the ratio of standard deviations to be .186 and the correlation coefficient 253 .
} 
and the predicted dividend yields from each rolling VAR estimation as a dependent variable, and $\log$ quarterly volatility of daily total REIT returns as an independent variable. The idea behind this setup is that, after having accounted for variation in the dividend yield that is due to cash flow and interest-rate information, we should have approximately isolated a component of variation that should be related to time-varying risk premia, which in turn should be driven at least in part by a measure of risk. If, on the other hand, we have not isolated this component to enough of an extent (namely by subtracting from actual dividend yields a component of variation in the dividend yield that does not satisfactorily capture cash flow- and interest-related components of variation), we should see other components of variation potentially overpower that component related to timevarying risk premia, and thus obtain a model that is only noise.

In these regressions we do not find a significantly positive effect of log REIT return volatility on either the overall log dividend yield itself (we run this model for calibration purposes), or on observed dividend yield minus predicted dividend yield generated with REIT dividend-variables and interest rate only. We do find, on the other hand, that log REIT return volatility has a significantly positive effect on both the log difference computed with dividend yields predicted using logs of REIT dividend yield, REIT dividend growth, NOI yield, and interest rate, as well as that computed with dividend yields predicted using logs of REIT dividend yield, NOI yield, NOI growth, and interest rate. While we must approach these results with caution, as the coefficients are only significant at the ten-percent level and the R-squareds are only .0482 and .0434, these results do seem to lend support to our hypothesis that direct property cash flow information plays an important role in determining REIT prices, and more generally that cash flow information, when measured correctly, constitutes an important determinant of asset prices in general. This applies especially if one considers that realized quarterly volatility only incompletely accounts for risk-related pricing information (which must be forward looking).

The rest of this study proceeds as follows. Section 2 presents the investigation on how innovations in state variables affect returns. Section 3 presents the empirical methodology and results for the dividend yield models. Section 4 concludes. 


\section{Returns and Dividend Innovations}

We begin our analysis by looking at the connection between asset returns and fundamentals in our data set. The standard approach in financial economics holds that fluctuations in asset prices are attributable to changes in fundamental values. The connection between asset values and fundamentals is expected to hold in different asset markets. In this section we compare results from three markets-the stock market, Real Estate Investment Trusts (REITs), and directly held real property (Direct Property market).

Several classic studies have looked at what fraction of asset returns can be attributed to the arrival of news. Our approach in this section is similar to Cutler, Poterba, Summers (1989) who study the impact of economic news on stock prices. Their study estimates the fraction of variation in aggregate stock returns that can be attributed to various types of economic news. Cutler et. al. (1989) find that their news proxies can explain approximately one-fifth of the variance in stock returns. As a fist step, we set out to investigate whether real estate data-with its potentially better identification of cash flows-allows to examine how an asset market moves in response to information about cash flows and economic fundamentals.

As described in the previous section, one advantage of working with real estate data is a better measurement of cash flows to investors. One challenge, however, is limited time series of real estate data. The comprehensive real estate data set available to us has quarterly observations of returns and cash flows covering the period from 1978 through 2007. This is a shorter time span than traditionally examined in the stock market studies. We start with less structured analysis of the data. In this section we investigate whether dividend innovations contain information that explains variation is asset returns. Having established informational contents of the data within a less structured framework of this section, we will proceed with more structured tests of dividend pricing model in the next section of the paper.

\subsection{Methodology: Evidence from VAR Innovations}

For each data set we work with, our analysis has two parts. First, we estimate Vector Autoregression (VAR) model relating each economic variable to its own history and to that of the other variables. 
We create a set of several state variables, $\mathbf{X} \equiv X_{1}, \ldots, X_{K}$ and use VAR models to identify the unexpected component of each time series. Second, we study the explanatory power of the unexpected components-the news-in explaining returns on stocks, REITs, and direct properties.

We analyze returns in two stages. In the first stage we fit a VAR model to explain joint behavior of the state variables. We estimate VAR system with $L$ lags for a vector of state variables, $\mathbf{X}$,

$$
\begin{gathered}
X_{1, t}=\alpha_{1,0}+\sum_{i=1}^{L} \alpha_{1, i} X_{1, t-i}+\sum_{j=2}^{K} \sum_{i=1}^{L} \alpha_{j, i} X_{j, t-i}+\widehat{\zeta}_{1, t} \\
\vdots \\
X_{K, t}= \\
\alpha_{K, 0}+\sum_{i=1}^{L} \alpha_{K, i} X_{K, t-i}+\sum_{j=1}^{K-1} \sum_{i=1}^{L} \alpha_{j, i} X_{j, t-i}+\widehat{\zeta}_{K, t}
\end{gathered}
$$

The above VAR approach has an important, and conceptually attractive, characteristic. VAR takes into account joint dynamics of the state variables, and accounts for mutual impact of the variables. In this setting, innovations represent news after the mutual impact of the variables has been taken into account. This is an important difference between the VAR-based approach that we use and, for example, the "factorization" approach. In the latter, the returns on an asset class are decomposed into several components, each related to a factor. Factors are assumed to be orthogonal to each other. Studies based on the factorization approach are designed to assess relative importance of independent (by assumption and by construction) factors (see, for example a study by Clayton and MacKinnon (2003)). A VAR-based study allows to focus on the role of innovations in the state variables in explaining returns, after joint dynamics of the system has been modeled. This is especially important when economic variables (such as short-term and long-term interest rates, industrial production, and money supply) are included in the system together with financial variables (returns, dividends, and volatility).

The state variables we use in the analysis are chosen to measure cash flows, economic conditions, risk, and the risk-free discount factor. We work with:

1. The logarithm of real dividend payments. Three dividend series is used in the analysis. For the stock market, the dividend series are the dividends on CRSP stock market index. For the 
REITs, the dividend series are the dividends on a REIT index. For direct property, dividends are computed from the Net Operating Income (NOI) data collected by NCREIF.

2. The nominal long-term interest rate, measures as Moody's AAA corporate bond yield.

3. The nominal short-term interest rate, measured as the yield on three-month Treasury bills.

4. The logarithm of stock market volatility.

5. The logarithm of REIT return volatility.

6. The logarithm of industrial production.

7. The logarithm of real money supply (M1).

Each VAR equation also includes a time trend and a set of indicator variables for different quarters. We treat the residuals from these equations (denoted $\widehat{\zeta}_{1, t}, \ldots, \widehat{\zeta}_{K, t}$ ) as economic news and use them as explanatory variables for returns. Because VAR system accounts for the joint dynamics of the variables, the residuals also reflect the fact that mutual impact of the variables in the system has been taken into account.

In the second stage we regress returns on news in the state variables:

$$
R_{t}=\beta_{0}+\beta_{1} \widehat{\zeta}_{1, t}+\ldots+\beta_{K} \widehat{\zeta}_{K, t}+\epsilon_{t}
$$

We perform this regression for returns on stocks, REITs, and direct property returns. $R_{t}$ is the real, dividend-inclusive return. The variables on the right-hand-side are the news variables. The $\bar{R}^{2}$ for this regression measures the fraction of the return variation that can be explained by our righthand-side variables. In other words, it measures the importance of innovations in the explanatory variables in explaining movements in asset prices. By applying this methodology to returns on the three types of assets (stocks, REITs, direct property) we can investigate the role that different explanatory variables play in each market. 


\section{$2.2 \quad$ Data}

Our data on economic variables (long-term interest rate, short-term interest rate, industrial production, and money supply) is from the data base maintained by St. Louis Federal Reserve Bank. We also obtain monthly CPI inflation rate from the same source. Nominal returns and nominal dividends are converted to real values using the inflation rate.

The information for the direct property market is derived from the data provided by the National Council of Real Estate Fiduciaries (NCREIF). NCREIF collects data on Net Operating Income (NOI) and appraisals for a large portfolio of real estate properties. This data set includes returns and income (dividends) on a portfolio of direct properties. The data is quarterly and covers the period from 1978 to 2007. We perform all our analysis (for stocks, REITs and direct properties) using quarterly frequency for this time period.

Our data on REITs comes from the Center for Research in Security Prices (CRSP). We construct a market-value-weighted portfolio of REITs and compute a series of quarterly returns, and a series of quarterly dividends for the portfolio. We use CPI inflation series to compute real returns and real dividends and use real values throughout the analysis.

We use two measures of risk: the logarithm of stock market volatility, and the logarithm of REIT return volatility. Volatility is defined as the variance of daily returns in the quarter. For stock volatility, we use daily returns on the CRSP value-weighted index that includes NYSE/AMEX/NASDAQ. For REIT volatility, the returns are daily returns on the value-weighted REIT portfolio.

\subsection{Results and Implications}

Before focusing on the evidence from the real estate asset market, we use the stock market as the benchmark. Results for stock returns are presented in Table 2. The table reports estimates of the regression equation for stock returns on innovations in the state variables. The data are quarterly and cover the whole time period 1978-2007. The dependent variable is the real return on CRSP value-weighted portfolio of stocks. The dividend series are real dividends on the stock market index.

Several conclusions emerge from this table. The main specification includes innovations in 
dividends, stock market volatility, and macroeconomic variables. In this setting, news explain approximately one-fifth of the movement in stock prices $\left(\overline{R^{2}}\right.$ equals 0.222 when VAR is estimated with 1 lag and equals 0.216 when 2 lags are included in the VAR). These results are a little better than the $\overline{R^{2}}$ of 0.185 reported in a similar regression by Cutler, Poterba, and Summers (1989), who may benefit from better statistical power because they work with monthly series spanning a longer time period (1926-1985). Our next conclusion is that innovations in dividends are an important source of return variability. The coefficient for dividends is significant at $5 \%$ (or at $1 \%$ ) in all specifications.

We also find that innovations in volatility are important for explaining asset returns. When we omit the volatility variable from the regressions, the $\bar{R}^{2}$ drops from above $22 \%$ to the level of $10 \%$ or below, suggesting the importance of volatility innovations as explanatory variable. When included in the regression, volatility innovations variable is significant at $1 \%$ level. The results for dividend and volatility innovations are similar to those reported by Cutler, Poterba, and Summers (1989).

Table 3 reports estimates of the regression of direct property returns on innovations in explanatory variables. The dependent variable is the real return on directly held real estate properties. The quarterly data are from the NCREIF data base. To capture news in income (dividends) we work with two variables. The first is the direct property dividend (net operating income), and the second is the dividend on REIT index. Both variables reflect conditions in the real estate market. Changes (news) in each of these two variables can be potentially relevant for explaining returns in the direct property market. We also use two measures of volatility. It is difficult to construct a measure of volatility for the direct property market. Return observations are available at quarterly frequency, and therefore using high frequency returns to construct volatility measure is not possible. We use two measures of volatility: stock market volatility and volatility of REIT returns.

Panel A of Table 3 reports results when both measures of volatility are included. When dividend innovations are measured by direct property dividends, news explain approximately $8 \%$ of return variation $\left(\overline{R^{2}}\right.$ equals 0.082$)$. Innovations in dividends are statistically significant at $1 \%$ level. This result holds when only REIT volatility is used to measure risk (panel B), or when risk is measure by 
stock market volatility (panel C). Our first result is that innovations in direct property dividends are important for explaining returns in the property market. The second result is that innovations in economic variables (industrial production and real money supply) are also significant in many specifications. These variables were not significant in regressions for stock returns. Third, the results reflect the challenge of finding an appropriate measure of risk for the direct property market. Neither the stock market volatility innovations, not REIT volatility innovations are significant in the case of direct property returns. The results suggest that using REIT volatility as a measure of risk in the direct property market does not help explain direct property returns. This may also explain why $\overline{R^{2}}$ in direct property regressions are lower than those in the stock market regressions and REIT regressions. In the latter two cases better measures of risk are available.

Table 4 reports results for REIT returns. The dependent variable is the real return on a portfolio of REITs. Two dividend series are used: direct property dividends and REIT dividends. Also, two measures of volatility are used: stock market volatility, and volatility of REIT returns.

When both dividend series and both volatility measures are included (panel A, last specification), news explain more than one-fifth of the movement in REIT values $\left(\overline{R^{2}}\right.$ equals 0.238$)$. Volatility is an important explanatory variable. Panel B of Table 4 reports results when REIT volatility is used as a measure of risk. The variable is statistically significant in all specifications at $1 \%$ level. Panel $\mathrm{C}$ reports results when stock market volatility is used as a measure of risk. The variable is also significant as $1 \%$ level, but the $\bar{R}^{2}$ are somewhat lower. This suggests that innovations in stock market volatility do not do as well in explaining variation in REIT prices, as innovations in REIT volatility. In either case, however, a measure of risk is important. Innovations in REIT dividends are also important. This variable is significant at $5 \%$ (or higher) level in all specifications.

We work in a challenging environment of relatively short time series and quarterly observations. In this setting, we are able to establish that dividend innovations are important in explaining real estate asset returns. We do it in a VAR setting that accounts for joint dynamics of the state variables. The connection between dividends and asset prices is established for both the direct property market and for REITs. Therefore, in the next section we proceed to more direct tests of 
the dividend pricing model.

\section{Taking Advantage of the Parallel Asset Markets to Assess the Performance of Dividend Pricing Models}

\subsection{Modeling the Dividend Yield}

We now turn our attention to dividend pricing models, as a useful approach in attributing the variability of asset returns. This approach has been taken frequently in the asset pricing literature (see for example Shiller (1987), Campbell and Shiller (1988a,b), Campbell (1991), and especially Kallberg et al. (2003), who test this approach for REITs). This framework can be summarized as follows.

In a basic view, a financial asset can be seen as simply a claim to all future cash flows this asset offers, and thus can be priced as the present discounted value of all these cash flows. With equity, these cash flows will consist of dividends paid out by a firm, and so a share of stock should be priced as the present discounted value of all future dividends, or

$$
P_{t}=\sum_{k=1}^{\infty} \gamma_{t+k}^{k} D_{t+k}
$$

In this formulation, the stock price today, $P_{t}$, is the sum of all future dividends (assuming an infinite life time for the firm), discounted by a possibly time-varying discount factor $\gamma_{\tau}<1$, and thus this formulation is called a dividend pricing model. Since the right-hand side of equation 1 concerns future cash flows, the stock price $P_{t}$ will in reality be based on expectations of future dividends $\left(E\left[D_{t+k}\right]\right)$, and (assuming a time-varying discount factor) also on expectations of future discount factors $\left(E\left[\gamma_{t+k}\right]\right)$.

A further modification in the approach to equation 1 will allow an additional insight. The stream of expected future dividends, $E\left[D_{t+1}\right], E\left[D_{t+2}\right], E\left[D_{t+3}\right], \ldots$, given the current observed dividend, $D_{t}$, can be seen as a product of the current dividend and an expectation of the dividend growth rate 
$E\left[\Delta D_{t+k}\right]$, which means that, given today's dividend, asset prices depend solely on the market's expectations of future discount factors and dividend growth rates.

$$
P_{t}=D_{t} E\left[\sum_{k=1}^{\infty} \gamma_{t+k}^{k} \Delta D_{t+k}\right]
$$

It is therefore intuitively appealing to examine the dynamics of asset prices conditional on the current dividend, in that this provides insight into the component of variation in asset prices that is due to the market's processing of current cash flow and discount rate information, by making predictions of both discount rates and dividend growth rates into the indefinite future. This provides an intuitive explanation for why a high degree of attention has been devoted to modeling dividendprice ratios or dividend yields ${ }^{4}$ (in the above notation $D_{t} / P_{t}$ ), and why we now turn our attention to this measure.

\subsection{Why REITs?}

Real Estate Investment Trusts (REITs) offer distinct advantages in applying dividend pricing models in several respects. Firstly, REITs are mandated by law to pay out at least $90 \%$ of their taxable income as dividends (this figure was $95 \%$ before 2000). However, while this regulation is in place in order to make REITs more like pass-through investment vehicles, in reality this is not a particularly binding constraint, in that a REIT's taxable income is generally low in comparison with its overall cash flows, due to the high amounts of depreciation a REIT can deduct, due to its property holdings. Thus, while to some extent, there is a constraint placed on REITs' dividend policy and these firms' ability to manage dividends (thus apparently making their dividend stream a better proxy for their true underlying cash flows than that of other firms), there is still a large heterogeneity of dividend payout ratios, indicating that a large amount of discretion exists on the part of management in determining dividends. Kallberg et al. (2003), for example, find that out of the 50 largest REITs in 1999, only three paid out the required $95 \%$, while the median payout ratio lies at $111 \%$, and

\footnotetext{
${ }^{4}$ This is a vast literature which we do not attempt to summarize here. A useful overview of this line of literature is given in Campbell, Lo and MacKinlay (1997).
} 
the distribution of REITs' payout ratios extends well above this number. Due to the misleading nature of the taxable income figure with respect to REITs, the industry uses Funds From Operation (FFO) as a cash flow measure, which adjusts, among other things, for depreciation. ${ }^{5}$ While there is less dispersion in the percentage of FFO that REITs pay out as dividends (the median figure here lies at $85 \%$, according to Kallberg et al. (2003)), there is still some dispersion (the authors find that $84 \%$ of firms pay between 70 and $105 \%$ of FFO), which may indicate some degree of dividend management by REITs, and therefore even for REITs, dividends remain a noisy proxy of the firm's underlying cash flows, and thus of the cash flows investors perceive equity ownership entitles them to. However, it does seem to be the case that the dividend payout constraint (or perhaps the custom of paying out a large percentage of cash flows as dividends) does add at least somewhat more information content to REIT dividends than what one finds in the dividend of other firms.

A second factor which should increase the overall informativeness of REIT dividends lies in these firms' relative transparency, which may make signaling through dividends less of a motivation for dividend management, since there is generally less informational asymmetry, and therefore less necessity for this. Wang, Erickson and Gau (1993), for example, document that while REIT prices tend to exhibit abnormal returns upon dividend announcements, the magnitude of these returns is only about $40 \%$ that of ordinary equities. Thus, while one must approach both of these points with some degree of caution, it does seem to be the case that dividends themselves offer a greater information content about the perceived cash flows of the firm in the case of REITs, when compared to other equities. This explains the results of Kallberg et al. (2003).

There exists a second advantage in using REITs to determine the relative importance of cash flows versus market predictions on growth rate and discount factors, in the dynamics of prices. Because REITs generate their cash flows by holding and operating commercial real estate, and commercial real estate returns themselves are generally observable, it is possible to use returns data directly from the commercial property market, to proxy for data on REIT cash flows and supplement the information content of dividends. For example, the cash flows a REIT earns by holding a property of a particular type (say, an office building) in a particular city (say, New

\footnotetext{
${ }^{5}$ Further adjustments include amortization as well as revenues from unconsolidated partnerships and joint ventures.
} 
York City) should be closely related to the overall rental cash flows that the market for New York office buildings gives at that time. Similarly, in aggregate, the dynamics of the cash flows earned by the REIT industry as a whole, should be closely related to those of the cash flows a broad nationally diversified portfolio of commercial properties of the same type generates. This study's contribution in this respect lies in exploiting this relationship between the two asset markets, by adding direct-property returns data to the cash flow information set on which a dividend pricing model is tested.

\subsection{The Empirical Approach}

In the Campbell and Shiller (1988a,b) framework, dividend pricing models are tested by attributing a component of the variation in the dividend yield to a part of the investor's information set which is linked to the dynamics of dividends. If this component does not constitute a sufficiently high fraction of the overall observed variation in the dividend yield, the dividend pricing model is rejected. In order to model the dividend yield based on this information set, Campbell and Shiller employ a Vector Autoregression (VAR), and we follow their technique, and for the purpose of this exposition largely borrow their notation.

It is clear from equation 2, that while the dividend yield $\left(D_{t} / P_{t}\right)$ is a function of expected dividend growth rates and discount rates, this relationship is non-linear, and it would therefore not be possible to model this variable within the linear framework of a VAR. In order to remedy this, Campbell and Shiller re-write this equation in terms of natural logarithms of variables. In the limit as the prediction window becomes arbitrarily large, and assuming constant excess returns, Campbell and Shiller obtain what they term the dividend-ratio model, or the dynamic Gordon Model, a dynamic version of the Gordon Growth Model $^{6}$ in which expected dividend growth rates, as well as, to a certain extent, discount factors can vary through time:

\footnotetext{
${ }^{6}$ In the Gordon Growth Model, both the discount rate and the dividend growth rate are assumed to be constant through time, and so the dividend yield becomes an exact linear function of the discount rate $(r)$ and growth rate $(g)$, or $D_{t} / P_{t}=r-g$.
} 


$$
\delta_{t}=\sum_{j=1}^{\infty} \rho^{j} E_{t}\left[r_{t+j}-\Delta d_{t+j}\right]+C
$$

This version of the dividend ratio model assumes that, while the risk-free interest rate can vary through time, the excess return is constant. In this representation, $\delta$ is the log of the dividend yield, $r_{t+j}$ is the return to an alternative asset (a proxy for the risk-free rate) during the time period ending $j$ periods from now, $\Delta d_{t+j}$ is the dividend growth rate during this time period, $\rho$ is the ex-post observed discount factor, and $C$ is a constant relating the observable discount rate to the actual, unobservable discount rate.

It is now possible to model the time-series dynamics of the dividend-ratio model through a VAR consisting of the variables $\delta_{t}$ and $r_{t}-\Delta d_{t}$, the growth-adjusted interest rate. Since this is just a restricted form of a three variables VAR system, modeling $\delta_{t}$, and $\Delta d_{t}$ and $r_{t}$ separately, we elect to use this latter specification. Thus, with only one lag, the basic VAR we estimate becomes:

$$
\left[\begin{array}{c}
\delta_{t} \\
\Delta d_{t} \\
r_{t}
\end{array}\right]=\left[\begin{array}{ccc}
a_{11} & a_{12} & a_{13} \\
a_{21} & a_{22} & a_{23} \\
a_{31} & a_{32} & a_{33}
\end{array}\right]\left[\begin{array}{c}
\delta_{t-1} \\
\Delta d_{t-1} \\
r_{t-1}
\end{array}\right]+\left[\begin{array}{c}
u_{1, t} \\
u_{2, t} \\
u_{3, t}
\end{array}\right]
$$

In this representation, $a_{i j}$ are the regression coefficients and $u_{i, \tau}$ are error terms, while all other variables are as defined above. We also estimate augmented versions of this system which include direct-property cash flow variables, creating systems of up to five variables and including up to two lags. ${ }^{7}$ We de-mean all data, in order to be able to specify these systems without a constant.

The system in equation 4 can be written more compactly in matrix form as

$$
z_{t}=A z_{t-1}+v_{t}
$$

where $z_{\tau}$ is the observed vector of state variables at time $\tau, A$ is the matrix of coefficients, and

\footnotetext{
${ }^{7}$ For details on the exact regressions we estimate as well as variable definitions, please see section 3.4.
} 
$v_{t+1}$ is the vector of error terms. Economically, it can be argued that the vector of state variables $z_{t}$ contains all present and past information concerning the variables in this vector. Therefore, in order to construct a forecast of this vector $k$ periods ahead, conditioned upon this information set, one simply needs to multiply $z_{t}$ by the matrix of VAR coefficients $A$ raised to the $k$ power. In other words, forecasts are computed as

$$
E\left[z_{t+k}\right]=A^{k} z_{t}
$$

We proceed by estimating various versions of this VAR system over a 40-period rolling window (i.e. at any time $t$ we use observations from $t-39$ to $t$, to generate $A_{t, t-39}$ ) and creating a one-period out-of-sample forecast $\delta_{t+1}^{\prime}$, which economically represents the portion of the dividend yield that is entirely based on the information contained in the state vector used. We then draw statistical comparisons between the series of forecast dividend yields based on only cash flow and interest rate information, and the ex-post realized dividend yield for the same period $\left(\delta_{t+1}\right)$, in order to determine how well the overall dynamics of the dividend yield are explained by these state variables. Since none of our state variables concern time-varying risk premia, we posit that the portion of dividend yields that is not forecast by our VAR will be largely due to this component, and conduct basic tests for this hypothesis, using the difference between forecast and observed dividend yields.

Note that our empirical approach differs slightly from that of Campbell and Shiller (1988a,b) and Kallberg et al. (2003), in that these earlier studies estimate the matrix of coefficients $A$ over the entire sample, and generate their predicted values $\delta^{\prime}$ as essentially just fitted values from the VAR. Our approach seems advantageous in this respect, in that by predicting $\delta^{\prime}$ out of sample, we use only information about state variables that truly was available to market participants at that particular time. Further, by doing this, we allow the nature of the cash flow and interest rate processes to vary through time, which these previous studies do not do. Our technique also demonstrates that even with a relatively short estimation period upon which $A$ is estimated, ex-post reasonable estimates can be generated from this data. Finally, by using only one-quarter forecasts and not a sum of infinite-horizon forecasts, we do not need to pick an exogenous discount factor $\rho$, 
since we do not need to produce a bounded sum of future growth rates. The implication here would simply be that the VAR coefficients we estimate differ from the true weightings the market places on these sources of information by a cross-sectionally consistent multiplicative constant. Since we do not place much interest on the size of the coefficients we obtain, this should not matter to our analysis.

\subsection{Data and Methodology}

The innovation of this study within the framework of modeling the dividend yield lies in adding information related directly to the underlying property market to the traditional REIT dividend information, in order to more closely proxy for the overall cash flow information, with which an investor or analyst might be able to make forecasts. This information is derived from the data provided by the National Council of Real Estate Fiduciaries (NCREIF). NCREIF collects data on Net Operating Income (NOI), as well as appraisals from a large portfolio of institutional-grade commercial properties. Table 1 shows the total appraised value of the portfolio NCREIF follows, in comparison with the total estimated market capitalization of publicly-traded REITs at the end of each year since 1980. It should be apparent from this comparison that the size of the portfolio followed by NCREIF is similar to that of the overall REIT industry. The properties on which NCREIF collects data are held by private institutions such as commingled real estate funds. It is widely documented that the appraisal values used in this data are somewhat problematic, in that they suffer from various types of appraisal bias. However, in this part of the study, we only use Net Operating Income (NOI), which is simply the quarterly operating cash flow for each property, reported to NCREIF directly, and which therefore should not suffer from these problems. ${ }^{8}$ The types of commercial property covered by NCREIF are Apartment, Hotel, Industrial, Retail, and Office. When we construct the REIT data we only retain equity REITs which invest in these types

\footnotetext{
${ }^{8}$ Net Operating Income consists of rental revenue (as well as other ancillary income, such as parking revenue, billboard space, etc.) minus operating expenses. Capital Expenditures made on the property are not part of NOI, as these are not considered part of the property's normal operations. While we also have data on CapEx, we elect to exclude this quantity from our direct-property cash flow measure, as economically this should not constitute an industry-wide systematic expenditure, to which REITs would necessarily also be exposed.
} 
of properties in our sample. ${ }^{9}$ This data is of quarterly frequency, and this is the frequency we use throughout this study. We obtain NOI per square foot values from this dataset, disaggregated by property type. We then use weights based on the relative market capitalization of the REITs that invest into this property type, in order to form a weighted average quarterly NOI per square foot, which becomes our basic direct property cash flow measure. Table 1 shows these weights as of the end of each year. Weights are computed quarterly, based on REITs' relative market capitalization at the end of the previous quarter.

The direct-property NOI variable has two very desirable properties in terms of the information content on direct property cash flows it provides. Firstly, as mentioned above, the properties in the NCREIF dataset are held by institutions which are not publicly traded. Therefore, the managers of these property portfolios have no adverse market overreaction to fear, upon reporting lowerthan-expected cash flows, a common explanation for the incentive to smooth dividends and even earnings for publicly traded firms. Secondly, the NOIs for each individual property is reported to NCREIF in private under a strict non-disclosure agreement, and NCREIF then only publishes these returns in aggregate. This should further mitigate the incentive for managers to smooth or mask low cash flows for a particular quarter.

Our data on REITs comes from the Center for Research in Securities Prices (CRSP). We identify and use all equity REITs which invest into the five types of property that NCREIF covers, and form a value-weighted portfolio, using market capitalizations from the end of the previous quarter (quarter $t-1$ ) to compute weights for quarter $t$. This procedure makes this portfolio tradeable. Further, at the end of each quarter, we record the market capitalization of all the firms we identified as investing into the NCREIF property types as a fraction of total REIT market capitalization that quarter (end-of-year snapshots are reported under Fraction Matched in Table 1, as well as the market capitalization associated with each of our five property types, as a fraction of all firms we were able to match (end of year snapshots are reported under each property type heading in Table 1). ${ }^{10}$ These fractions serve as weights to construct the weighted-average NOI per square foot

\footnotetext{
${ }^{9}$ Further, until 1983 the NCREIF portfolio does not contain any Hotel properties, and thus we eliminate Hotel REITs from our sample before this time.

${ }^{10}$ Once again, since NCREIF does not cover any hotel properties until 1983, we exclude these REITs from our sample until then.
} 
coming from NCREIF. Our data starts in 1980

The basic variables we then construct for this portfolio are a series of quarterly weightedaverage total returns (variable RET in CRSP), which includes dividends and other distributions, and a series of quarterly weighted average price returns (variable $R E T X$ in CRSP), which consists of quarterly price movements only. We then construct a series of weighted average dividend yields, which at time $t$ is defined as the total weighted average distributions during quarter $t$ divided by the price at the end of quarter $t$, as well as a series of quarterly weighted-average dividends for the REIT portfolio, both of which are constructed as functions of the total return and price return series, and (as is customary with index-type construction) are defined up to an arbitrary multiplier, which is consistent through time. For details on the construction of these series, see Appendix A. We further construct a REIT price index, which we set to a value of 100 in the last quarter of 1979, and we then compute as 100 times the geometrically compounded price return figures. The REIT variables we use in our analysis are the natural logarithm of the dividend yield (div.yield), and the $\log$ of the quarterly dividend growth rate ( $\Delta$ dividend), which is defined as the difference of the logs of the dividends paid in quarter $t$ and in quarter $t-1$.

We further define the variable (noi.yield), as the natural log of the ratio of weighted-average NOI per square foot over the end-of-quarter level of the REIT price index mentioned above. Once again, this variable is defined only up to an arbitrary multiplier which is constant through time. ${ }^{11}$ The other direct-property cash flow variable we use is $\Delta$ noi which is the first difference in the natural logs of quarterly weighted-average NOI per square foot figures, and represents the quarterly growth rate of direct property cash flows.

The final variable we use for this part of our analysis is lt.rate which is defined as the natural $\log$ of the long-term interest rate as of the end of quarter $t$. We use the 30-year US Treasury Bond rate where available, and otherwise the 20-year US Treasury Bond rate. Note that Campbell and Shiller (1988a,b) use short-term interest rate for their analysis. We elect to use the long-term interest rate, because this variable offers a better idea of the market's indefinite forecast of future risk-free rates. While we only construct one-quarter forecasts in the dividend yield from our VAR,

\footnotetext{
${ }^{11}$ Because we de-mean all data in our VAR analysis, the size of these multipliers should be irrelevant for all variables, even those that are not defined as a log difference.
} 
economically these should still constitute the market's best forecast in the combination of dividend growth rate, cash flow growth, and the risk-free rate, over the indefinite future, and so the choice of a long-term interest seems warranted.

\subsection{Results and Implications}

Before proceeding to a discussion of the results from our VAR procedure, we present a simple and preliminary test designed to illustrate that the time-series dynamics of our noi.yield measure behave as we would expect those of a dividend yield to behave. This in turn should constitute preliminary evidence that direct property NOIs give useful information for the cash flow-related portion of REIT price movements. Specifically, we run a simple OLS regression of the first difference in div.yield on the first difference in lt.rate, and compare this to a regression of the first difference in noi.yield on the change in lt.rate. Note that all variables are logs of their raw data series, and so these first differences approximate fractional changes in these series. Economically, since the dividend yield consists in part of the risk-free rate, a change in the latter should cause a change in the former, with the two changes being positively related. Conversely, if noi.yield does not resemble a dividend yield at all (most likely because NOIs do not yield useful information about REIT cash flows and therefore REIT prices), fluctuations in NOI yield would be less likely to be explained by fluctuations in the long term rate.

Table 5 shows the results from these two regressions. In Model 1, where the dependent variable is the change in the actual REIT dividend yield, the point estimate for the coefficient for changes in the interest rate is actually negative, and in any case statistically insignificant. For Model 2, on the other hand, the coefficient for the interest rate is positive, and somewhat statistically significant (at the $10 \%$ level). The $R^{2}$ from Model 2 is .027 , about twice that from Model 1 . While in either

case the interest rate does not explain a large portion of the variation in yields, this relationship does seem to be slightly better for NOI yields. In a test not reported here, however, we find that the distributions of the squared residuals from each model, scaled by the total variance of that model's dependent variable are not statistically distinguishable from each other. While some different explanations could be given for these results, we can still cautiously state that Model 2 does 
present some preliminary evidence that the time-series dynamics of our NOI yield resemble those of a dividend yield, and that therefore direct-property NOIs do seem to contain useful information for REIT prices.

Table 6 presents the matrix of coefficients for the one-lag version of the most complete VAR system we estimate, estimated on the entire 1980-2007 sample, in order to illustrate some of the dynamics and interlinkages between our data series. Because both noi.yield and lt.rate have roots that are close to unity, we include a time trend variable in all systems. In the first line of Table 6 , we see that the dividend growth rate from the previous period negatively affects dividend yield, and that this effect is significant at the $5 \%$ level (coefficient of -0.2132 and t-statistic of -1.9961). Further, we can see that noi.yield the previous period significantly positively affects div.yield (coefficient of 0.1975 , t-statistic of 1.9099). This can be contrasted with the earnings yield used in Campbell and Shiller (1988b), which, while helping the VAR system as a whole, does not show a significant effect on the dividend yield next period. In this equation, the coefficient on the risk-free rate is positive and very significant. Together with the negative and significant coefficient on the dividend growth rate, this does coincide with the basic formulation of the Dynamic Gordon Model (equation 3), which models the dividend yield as a function of the growth-adjusted interest rate. One more issue of note about this equation is that its $\overline{R^{2}}$ is 0.5867 , while that of the equivalent equation in Campbell and Shiller (1988b) is 0.503, so we do explain a slightly higher fraction of the dividend yield with our direct-property cash flow measures than Campbell and Shiller do with earnings.

Of note in the second line of Table 6 , is the significantly positive coefficient on noi.yield (coefficient 0.2163 , t-statistic 2.2719 , which makes this coefficient $5 \%$ significant). This suggests that direct property cash flow information is relevant in predicting not just REIT dividend yields, but also REIT dividend growth rates. Besides this, the coefficient on $\Delta$ dividend may be of note, in that it is negative, while Campbell and Shiller (1988b) find this to be significantly positive. This may be due to intra-year autocorrelation patterns in dividends which are apparent in our quarterly data, but get smoothed out of the annual data Campbell and Shiller use.

Besides this, we can see from Table 6 that the three remaining variables are strongly autocor- 
related, noi.yield and lt.rate positively, and $\Delta$ noi negatively. Besides this, $\Delta$ dividend $_{t-1}$ seems to have a significantly negative effect on $\Delta n o i_{t}$. Economically this effect is difficult to rationalize, and we can perhaps ascribe it to different seasonality patterns in what is otherwise a pair of series that describe very similar information.

Table 7 presents the primary results from this section. For each quarter $t>40$, we estimate eight different VARs, over a rolling 40-quarter (10-year) time window and with the estimated coefficient matrix generate a predicted $\log$ dividend yield for the next quarter $t+1$ (pred.div.yield $\left.d_{t, t+1}\right)$. As mentioned before, intuitively this should be a dividend yield that only contains the information included in the VAR. We draw statistical comparisons between this predicted dividend yield and the ex-post realized dividend yield for quarter $t+1$. The reason we include only two lags in this table is because the full VAR system that contains both dividend and NOI growth rates becomes near rank-deficient at greater lags. While this prevents us from investigating higher-order lags, ${ }^{12}$ this is also quite informative, in that this shows that the dividend growth rate and the NOI growth rate contain very similar information. The table reports for each VAR specification, the ratio of the standard deviations of the predicted and the realized dividend yield, as well as the correlation between the two, together with a test statistic of the hypothesis that the true correlation between the two series is 0 . While, ideally, we should be pleased with the ratio of the standard deviations being as close to 1 as possible, in that this would presumably show that the VAR system is explaining a large fraction of the variation in realized dividend yields, one must approach this statistic with caution, since another reason why this statistic is high could simply be the fact that the predicted dividend yield is constructed very imprecisely, for example from noisy, unstable VAR coefficient matrices. Only in conjunction with a high correlation coefficient can we infer that the variation in the predicted dividend yield actually resembles that of the realized dividend yield.

VAR System 1 contains the benchmark model specification without direct-property cash flow measures, making this a specification that is comparable to that of Campbell and Shiller (1988a) and Kallberg et al. (2003). For one lag, we obtain a ratio of standard deviations of 0.6941 and a correlation coefficient of 0.4593 and this is nearly unchanged if we extend the VAR specification to

\footnotetext{
${ }^{12}$ For the sake of consistency we only use one and two lags for each of the other specifications, where this would not be the case.
} 
two lags. This closely resembles results of Kallberg et al. (2003), who obtain standard deviation ratios of 0.5970 and 0.7575 respectively, without conducting a rolling window VAR estimation. ${ }^{13}$ In the model estimated by Campbell and Shiller (1988a) that is closest to this specification, the ratios of standard deviations are 0.186 and 0.253 respectively, while the correlation coefficients are 0.395 and 0.383 . Thus despite the fact that we as well as Kallberg et al. (2003) use a quarterly frequency while Campbell and Shiller (1988a) use an annual frequency, it seems to be the case that REIT dividends themselves offer more pertinent information for forecasting dividend yields, than the dividends of other companies, in that we manage to explain a higher fraction of the variation in dividend yields with just these variables for REITs, and due to the higher correlation coefficient we can infer that this is not just due to more estimation noise, but that the variation in these predicted dividend yields really does follow that of actual yields more closely.

As is visible in the next panels of Table 7 , these results improve dramatically when directproperty cash flow variables are added to the rolling VAR system. When adding the noiyield in System 2, we find that the ratio of standard deviations increases to 0.9298 for one lag and 0.9563 for two lags, with the correlations at 0.6086 and 0.6847 , respectively. Adding the NOI growth rate, further improves these values to 0.9765 for one lag and 0.9813 for two, with correlations of 0.6503 and 0.7323 , respectively. Once again, while the increase in the ratio of standard deviations alone would not necessarily indicate better performance of these specifications over the benchmark model, the strongly increased correlations yield strong credibility to the idea that direct-property cash flows do proxy for important information in REIT price formation.

System 4 omits REIT dividend growth rate, and retains the two direct-market cash flow variables. This system performs especially well with two lags, where the ratio of the standard deviations is reduced to 0.9291, while the correlation figure is only reduced to 0.7313 (from 0.7323 in the full specification). The inference we draw from this is twofold. Firstly, it is probably the case that the reduction in the ratio of the standard deviations is due in large part to a reduction in estimation noise, since the correlation is almost unchanged. Secondly, and more importantly, however, it seems to be the case that the quarterly direct-property NOI growth rate contains more relevant

\footnotetext{
${ }^{13}$ Kallberg et al. (2003) do not report correlation coefficients of predicted and actual dividend yields.
} 
information to generating predictions about the future value to be derived from REITs, than the REIT dividend growth rate itself. This highlights the importance of the information contained in this measure in pricing REITs.

Figure 1 shows a plot of the predicted dividend yield (the red dashed line) and the ex-post realized dividend yield (the black solid line). Notice how closely the predicted dividend yields tracks many of the movements of the ex-post realized yield. This plot, together with the results in Table 7 presents strong evidence that cash flow information, when completely accounted for, does constitute a very important part of price dynamics. The problem with previous studies has simply been that it is very difficult to proxy the true underlying cash flows of a firm. With the unique opportunity that REITs offer, in that the direct property market yield an informative view of the firm's true cash flows, we are in fact able to show that a strong dependency exists between cash flows and security prices.

The final test we conduct in this section constitutes a preliminary attempt to model the nature of the residual variation in dividend yields, that is not explained by a state vector containing reliable cash flow proxies, and the risk-free rate. Economically, this variation should be brought about by time-varying risk premia, which determine a security's required outperformance over the risk-free rate. From basic intuition, these should be a product of the market-price of risk, and forecast volatility. If using logs, once again we should have a linear relationship here. Specifically, we run an OLS regression with as dependent variables the difference between the ex-post realized log dividend yield and the predicted log dividend yields from our VARs, and as an independent variable the $\log$ of realized volatility (variance) of daily total returns to the value-weighted REIT portfolio over the same quarter. While the risk measure that should enter into a dividend yield would need to forecast the entire expected term-structure of volatility, it would seem that the most recent realized volatility would feature prominently in the information set used to conduct such a forecast, and that therefore it should help explain at least some of the residual variation in dividend yields. Additionally, if the dividend yield still has too much other variation left in it (i.e. we have not isolated the risk-related component in its variation enough) this other variation, especially if not completely orthogonal to risk-related variation, might mask the component of variation that is 
due to volatility, yielding a noise relationship in this regression.

Table 8 shows the results from this regression. Note, first of all, that in the first column, where the dependent variable is the entire log dividend yield, the coefficient for volatility is indistinguishable from zero. As mentioned above, while presumably the overall dividend yield should at least in part be driven by volatility, it seems to be the case that the variation related to this variable is masked by other sources of dividend yield variation, leading to a noise regression. Following in this line of argument, we find practically no improvement over this in the second column, where we use the difference between realized dividend yields and the dividend yields predicted by VAR System 1, which has only dividend and interest rate variables, but no direct-property cash flow variables. It still seems to be the case that this predicted dividend yield does not account for enough of the cash flow-related variation in dividend yields, in order to isolate in a clean enough way, the component related to risk.

This situation, however, changes in the third column, where we use as a dependent variable the difference between the realized dividend yield and the predicted yield from VAR System 3, which adds NOI yield to the REIT dividend and interest rate variables. In this model, we find a positive coefficient of 0.0509 , with a t-statistic of 1.8298 , making this coefficient significant at the $10 \%$ level. From basic intuition, we would in fact expect a risk measure to have a positive effect on the dividend yield, as higher risk should increase the overall discount factor, and therefore lower prices relative to dividends. A similar situation can be found in the fifth column, where as a dependent variable we use the difference between the realized dividend yield and the predicted dividend yield from VAR System 4, which contains no REIT dividend growth, but only REIT dividend yield, NOI yield, NOI growth, and the risk-free rate. In this model we also have a positive significant coefficient of 0.0441 , with a t-statistic of 1.7311 , also making this coefficient significant at the $10 \%$ level. The $R^{2}$ between the two models is similar, at 0.0482 and 0.0434 , respectively. The model based on predicted dividend yields from System 3, does not exhibit a positively significant coefficient; however, the coefficient value for volatility, its t-statistic, as well as the model's $R^{2}$ are more comparable with the other models that contain predicted dividend yields based on direct property cash flow information, than with those that do not. It may be the case here, that the 
estimation error argument raised above becomes relevant in this case, in that the predictions from System 3 seem to be more noisy.

These results further validate the usefulness of reliable cash flow measures in modeling dividend yields. It seems that by modeling the cash flow-related portion of the variation in dividend yield more accurately, we are not only able to demonstrate the relative importance of true cash flow information in asset price formation, but we are also able to more cleanly isolate components of the dividend yield that are driven by time-varying risk premia.

\section{Conclusion}

In this study we examine sources of variability in asset returns within a framework of a dividend pricing model. We use data on Real Estate Investment Trusts (REITs) and on directly owned real estate. Thus, we supplement information on REIT cash flows with information on cash flows derived from the direct property market. We find that this fuller view of cash flow information significantly improves the performance of the dividend discount asset pricing model.

We first use a less structured approach to study the connection between cash flows and asset returns. We define a set of state variables that are chosen to measure cash flows, economic conditions, risk, and the risk-free discount rate. A VAR system that includes the state variables is estimated and residuals from the VAR represent the news (innovations) in the state variables. We then regress real returns on an asset class of interest (stocks, REITs, direct property) on innovations in the state variables. The $R^{2}$ for this regression measures the fraction of the variation in asset returns that can be attributed to various types of cash flows and economic news. We find that innovations in dividends are a central component in explaining return variation in our data set. For the stock market returns, we find that innovations in state variables explain approximately $22 \%$ of variation in returns. When we supplement REIT dividends with direct property dividends as state variables, we find that innovations in economic variables explain approximately $24 \%$ of REIT return variation. Overall, we establish that dividend innovations are important in explaining real estate asset returns.

When analyzing these relationships within the structural framework of the dividend pricing 
model, and more specifically by modeling the dividend yield, we find in basic tests that the timeseries dynamics of our direct-property NOI-based yield resemble those of a dividend yield, and that therefore direct-property NOIs do seem to contain useful information for REIT prices. Further, we are able to generate predicted dividend yields (based on information from REIT dividends and cash flow information from the direct property market) which closely resemble ex-post observed dividend yields. We are thus able to show that a strong dependency exists between cash flows and security prices, if this cash flow information is captured fully enough. Further, we demonstrate that by modeling the cash flow-related portion of the variation in dividend yield more accurately, we are also able to more cleanly isolate components of the dividend yield that are driven by time-varying risk premia.

Taken together, these findings suggest that better measurement of cash flows (dividends) can significantly improve the performance of dynamic dividend pricing models, and thus contribute to the resolution of the excess volatility puzzle. 


\section{References}

Ackert, L. F. and Smith, B. F.: 1993, Stock price volatility, ordinary dividends, and other cash flows to shareholders, The Journal of Finance 48(4), 1147-1160.

Campbell, J. Y.: 1991, A variance decomposition for stock returns, The Economic Journal 101(45), 157-179.

Campbell, J. Y. and Ammer, J.: 1993, What moves the stock and bond markets? a variance decomposition for long-term asset returns, The Journal of Finance 48(1), 3-37.

Campbell, J. Y., Lo, A. W. and MacKinlay, A. C.: 1997, The Econometrics of Financial Markets, Princeton: Priceton University Press.

Campbell, J. Y. and Shiller, R. J.: 1988a, The dividend price ratio and expectations of future dividends and discount factors, The Review of Financial Studies 1(3), 195-228.

Campbell, J. Y. and Shiller, R. J.: 1988b, Stock prices, earnings and expected dividends, Journal of Finance 43(3), 661-676.

Clayton, J. and Mackinnon, G.: 2003, The relative importance of stock, bond and real estate factors in explaining reit returns, Journal of Real Estate Finance and Economics 27(1), 39-60.

Cochrane, J. H.: 1992, Explaining the variance of price-dividend ratios, The Review of Financial Studies 5(2), 243-280.

Cochrane, J. H.: 2001, Asset Pricing, Princeton University Press.

Cochrane, J. H.: 2007, The dog that did not bark: A defense of return predictability, The Review of Financial Studies 21(4), 1533-1575.

Cutler, D. M., Poterba, J. M. and Summers, L. H.: 1989, What moves stock prices?, Journal of Portfolio Management 15(3).

Kallberg, J. G., Liu, C. H. and Srinivasan, A.: 2003, Dividend pricing models and reits, Real Estate Economics 31(3), 435-450. 
Lintner, J.: 1956, Distribution of incomes of corporations among dividens, retained earnings, and taxes, The American Economic Review 46(2), 97-113.

R Development Core Team: 2008, R: A Language and Environment for Statistical Computing, $\mathrm{R}$ Foundation for Statistical Computing, Vienna, Austria. ISBN 3-900051-07-0.

URL: $h t t p: / / w w w \cdot R$-project.org

Shiller, R. J.: 1981, Do stock prices move too much to be justified by subsequent changes in dividends?, The American Economic Review 71(3), 421-436.

Shiller, R. J.: 1987, Ultimate sources of aggregate variability, American Economic Review 77(2), 8792.

Wang, K., Erickson, J. and Gau, G. W.: 1993, Dividend policies and dividend announcement effects for real estate investment trusts, Journal of the American Real Estate and Urban Economics Association 21(2), 185-201. 


\section{A Appendix: Computation of Weighted-Average Dividend and Dividend Yield Series}

This section illustrates the method we use to compute the weighted-average dividend and dividend yield series for the value-weighted REIT portfolio. CRSP has two return figures: RET and RETX. $R E T$ is total holding period return, and $R E T X$ is holding period return excluding distributions. While both of these contain factors to adjust for stock splits, conceptually, we have:

$$
\begin{aligned}
R E T_{t} & =\frac{P_{t}+D_{t}}{P_{t-1}}-1 \\
R E T X_{t} & =\frac{P_{t}}{P_{t-1}}-1
\end{aligned}
$$

Thus, the dividend yield $y_{t}=D_{t} / P_{t}$ for our weighted portfolio is constructed as

$$
y_{t}=\left(\text { ret }_{t}-\operatorname{ret}_{t}\right) \times\left(\operatorname{ret}_{t}+1\right)^{-1}
$$

This is because

$$
\begin{aligned}
\left(\text { ret }_{t}-\text { ret }_{t}\right) \times\left(\text { ret }_{t}+1\right)^{-1} & =\left[\frac{P_{t}+D_{t}}{P_{t-1}}-1-\frac{P_{t}}{P_{t-1}}+1\right] \times \frac{P_{t-1}}{P_{t}} \\
& =\frac{D_{t}}{P_{t-1}} \times \frac{P_{t-1}}{P_{t}} \\
& =D_{t} / P_{t}
\end{aligned}
$$

Here ret $_{t}$ and retx $_{t}$ are the total returns and price returns respectively, to our value-weighted portfolio of REITs over quarter $t$. $P_{t}$ is the price at the end of quarter $t$, and $D_{t}$ the total dividend paid out over quarter $t$, to someone holding one share of the value-weighted index.

Subsequently, the dividend for quarter $t\left(D_{t}\right)$ is computed as the dividend yield above, multiplied by the level of our REIT price index. This figure is once again only correct up to an arbitrary multiplier that is consistent over time. However, since we use log-differences of this dividend series for our study, this is irrelevant. 
Table 1: Summary Statistics for REIT and Property Portfolios.

This table presents summary statistics for the REIT- and Direct Property data, as of the end of each year in our sample. The statistics presented are the total market capitalization of the REIT industry (in millions of Dollars), the fraction of market capitalization that we matched against NCREIF's property types (Apartment, Hotel, Industrial, Office Retail), the fraction of the matched portfolio market capitalization that is made up by each property sector, and the total appraised value of all properties in NCREIF's property universe (also in millions of Dollars).

\begin{tabular}{|c|c|c|c|c|c|c|c|c|}
\hline Year & $\begin{array}{l}\text { Total Industry } \\
\text { Capitalization }\end{array}$ & Fraction Matched & Apartment & Hotel & Industrial & Office & Retail & $\begin{array}{l}\text { Total NCREIF } \\
\text { Portfolio Value }\end{array}$ \\
\hline 1980 & 3,365 & 0.361 & 0.305 & 0 & 0.069 & 0.048 & 0.579 & 1,770 \\
\hline 1981 & 3,115 & 0.307 & 0.384 & 0 & 0.091 & 0.049 & 0.477 & 3,351 \\
\hline 1982 & 4,451 & 0.301 & 0.456 & 0 & 0.121 & 0.033 & 0.39 & 4,603 \\
\hline 1983 & 5,554 & 0.411 & 0.395 & 0.095 & 0.054 & 0.025 & 0.43 & 8,427 \\
\hline 1984 & 5,901 & 0.436 & 0.408 & 0.107 & 0.048 & 0.041 & 0.396 & 10,828 \\
\hline 1986 & 10,438 & 0.325 & 0.326 & 0.091 & 0.102 & 0.037 & 0.444 & 17,214 \\
\hline 1987 & 9,890 & 0.334 & 0.264 & 0.093 & 0.118 & 0.046 & 0.48 & 21,025 \\
\hline 1988 & 11,140 & 0.343 & 0.235 & 0.063 & 0.107 & 0.106 & 0.488 & 26,472 \\
\hline 1989 & 11,889 & 0.372 & 0.196 & 0.034 & 0.082 & 0.106 & 0.581 & 30,801 \\
\hline 1990 & 9,302 & 0.343 & 0.187 & 0.018 & 0.065 & 0.108 & 0.622 & 37,066 \\
\hline 1991 & 13,289 & 0.336 & 0.219 & 0.008 & 0.043 & 0.104 & 0.626 & 37,423 \\
\hline 1993 & 33,336 & 0.532 & 0.3 & 0.006 & 0.048 & 0.081 & 0.565 & 39,872 \\
\hline 1994 & 44,429 & 0.665 & 0.313 & 0.024 & 0.105 & 0.089 & 0.469 & 38,919 \\
\hline 1995 & 59,305 & 0.661 & 0.281 & 0.073 & 0.1 & 0.118 & 0.429 & 45,896 \\
\hline 1996 & 82,171 & 0.68 & 0.275 & 0.096 & 0.123 & 0.163 & 0.342 & 51,817 \\
\hline 1997 & 137,833 & 0.769 & 0.213 & 0.132 & 0.127 & 0.276 & 0.252 & 61,744 \\
\hline 1998 & 146,105 & 0.78 & 0.198 & 0.167 & 0.132 & 0.247 & 0.257 & 63,344 \\
\hline 1999 & 126,649 & 0.779 & 0.227 & 0.118 & 0.141 & 0.242 & 0.271 & 77,024 \\
\hline 2000 & 137,756 & 0.819 & 0.234 & 0.124 & 0.149 & 0.265 & 0.227 & 89,383 \\
\hline 2001 & 162,026 & 0.758 & 0.231 & 0.106 & 0.145 & 0.248 & 0.27 & 105,175 \\
\hline 2002 & 170,319 & 0.741 & 0.219 & 0.104 & 0.141 & 0.231 & 0.305 & 110,797 \\
\hline 2003 & 229,935 & 0.727 & 0.211 & 0.101 & 0.133 & 0.215 & 0.34 & 119,999 \\
\hline 2004 & 321,050 & 0.691 & 0.198 & 0.12 & 0.158 & 0.2 & 0.323 & 127,365 \\
\hline 2005 & 363,112 & 0.708 & 0.194 & 0.132 & 0.136 & 0.206 & 0.332 & 155,700 \\
\hline
\end{tabular}

Note that NCREIF's data contains hotels only from 1983 onwards. 
Table 2: Stock Returns.

The dependent variable is the real return on a value-weighted portfolio of NYSE, AMEX, and NASDAQ stocks on CRSP. Reported estimates correspond to the regression of real returns on innovations in predictive variables. Innovations are from a VAR system that includes all predictive variables, time trend, and quarterly dummies. Predictive variables are the logarithm of real dividends on the value-weighted stock index, long-term and short-term interest rates, the logarithm of volatility, the logarithm of industrial production, and the logarithm of the real money supply. Panel A includes real dividends over the most recent quarter. Panel B includes annual dividends-the average real dividends over the most recent four quarters. ( $t$-statistics in parentheses.)

\begin{tabular}{|c|c|c|c|c|c|c|c|}
\hline \multirow[b]{2}{*}{ Lags } & \multirow{2}{*}{$\begin{array}{l}\text { Real } \\
\text { Dividends }\end{array}$} & \multicolumn{3}{|c|}{ Interest Rates } & \multirow{2}{*}{$\begin{array}{l}\text { Industrial } \\
\text { Production }\end{array}$} & \multirow{2}{*}{$\begin{array}{l}\text { Real } \\
\text { Money }\end{array}$} & \multirow[b]{2}{*}{$\overline{R^{2}}$} \\
\hline & & Long & Short & Volatility & & & \\
\hline \multicolumn{8}{|c|}{ Panel A: Quarterly Dividend } \\
\hline 1 & $\begin{array}{l}0.215 \\
(2.383)^{* *}\end{array}$ & $\begin{array}{l}-0.836 \\
(-0.466)\end{array}$ & $\begin{array}{l}-0.908 \\
(-0.987)\end{array}$ & $\begin{array}{l}-0.063 \\
(-4.963)^{* * *}\end{array}$ & $\begin{array}{l}0.287 \\
(0.438)\end{array}$ & $\begin{array}{l}0.162 \\
(0.318)\end{array}$ & 0.222 \\
\hline 2 & $\begin{array}{l}0.336 \\
(3.078)^{* * *}\end{array}$ & $\begin{array}{l}-1.111 \\
(-0.608)\end{array}$ & $\begin{array}{l}-0.856 \\
(-0.857)\end{array}$ & $\begin{array}{l}-0.057 \\
(-4.271)^{* * *}\end{array}$ & $\begin{array}{l}0.607 \\
(0.816)\end{array}$ & $\begin{array}{l}-0.020 \\
(-0.036)\end{array}$ & 0.216 \\
\hline 1 & $\begin{array}{l}0.294 \\
(3.014)^{* * *}\end{array}$ & $\begin{array}{l}-0.809 \\
(-0.418)\end{array}$ & $\begin{array}{l}-1.038 \\
(-1.048)\end{array}$ & & $\begin{array}{l}0.414 \\
(0.575)\end{array}$ & $\begin{array}{l}0.191 \\
(0.341)\end{array}$ & 0.060 \\
\hline 2 & $\begin{array}{l}0.441 \\
(3.867)^{* * *}\end{array}$ & $\begin{array}{l}-1.009 \\
(-0.526)\end{array}$ & $\begin{array}{l}-0.914 \\
(-0.878)\end{array}$ & & $\begin{array}{l}0.707 \\
(0.912)\end{array}$ & $\begin{array}{l}0.010 \\
(0.016)\end{array}$ & 0.099 \\
\hline 1 & & $\begin{array}{l}-1.530 \\
(-0.871)\end{array}$ & $\begin{array}{l}-0.519 \\
(-0.573)\end{array}$ & $\begin{array}{l}-0.068 \\
(-5.322)^{* * *}\end{array}$ & $\begin{array}{l}0.217 \\
(0.325)\end{array}$ & $\begin{array}{l}0.094 \\
(0.182)\end{array}$ & 0.190 \\
\hline 2 & & $\begin{array}{l}-1.667 \\
(-0.919)\end{array}$ & $\begin{array}{l}-0.510 \\
(-0.521)\end{array}$ & $\begin{array}{l}-0.065 \\
(-4.830)^{* * *}\end{array}$ & $\begin{array}{l}0.401 \\
(0.524)\end{array}$ & $\begin{array}{l}0.006 \\
(0.010)\end{array}$ & 0.157 \\
\hline \multicolumn{8}{|c|}{ Panel B: Annual Dividend } \\
\hline 1 & $\begin{array}{l}0.837 \\
(2.878)^{* * *}\end{array}$ & $\begin{array}{l}-1.392 \\
(-0.769)\end{array}$ & $\begin{array}{l}-0.114 \\
(-0.119)\end{array}$ & $\begin{array}{l}-0.055 \\
(-4.242)^{* * *}\end{array}$ & $\begin{array}{l}-0.233 \\
(-0.344)\end{array}$ & $\begin{array}{l}0.258 \\
(0.493)\end{array}$ & 0.231 \\
\hline 2 & $\begin{array}{l}1.002 \\
(3.085)^{* * *}\end{array}$ & $\begin{array}{l}-1.348 \\
(-0.730)\end{array}$ & $\begin{array}{l}-0.348 \\
(-0.342)\end{array}$ & $\begin{array}{l}-0.053 \\
(-3.760)^{* * *}\end{array}$ & $\begin{array}{l}-0.138 \\
(-0.178)\end{array}$ & $\begin{array}{l}-0.027 \\
(-0.047)\end{array}$ & 0.214 \\
\hline 1 & $\begin{array}{l}1.163 \\
(3.861)^{* * *}\end{array}$ & $\begin{array}{l}-1.354 \\
(-0.707)\end{array}$ & $\begin{array}{l}-0.127 \\
(-0.126)\end{array}$ & & $\begin{array}{l}-0.289 \\
(-0.398)\end{array}$ & $\begin{array}{l}0.249 \\
(0.443)\end{array}$ & 0.105 \\
\hline 2 & $\begin{array}{l}1.384 \\
(4.243)^{* * *}\end{array}$ & $\begin{array}{l}-1.098 \\
(-0.573)\end{array}$ & $\begin{array}{l}-0.422 \\
(-0.406)\end{array}$ & & $\begin{array}{l}-0.376 \\
(-0.469)\end{array}$ & $\begin{array}{l}-0.038 \\
(-0.065)\end{array}$ & 0.122 \\
\hline
\end{tabular}

${ }^{*}: p<10 \%{ }^{* *}: p<5 \% ;^{* * *}: p<1 \%$. 


\section{Table 3: Direct Property Returns}

The dependent variable is the real return on a portfolio of directly held real estate properties. Reported estimates correspond to the regression of real returns on innovations in predictive variables. Innovations are from a VAR system that includes all predictive variables, time trend, and quarterly dummies. Predictive variables are the logarithm of real dividends (both for directly owned properties and for REITs), long-term and short-term interest rates, the logarithm of volatility, the logarithm of industrial production, and the logarithm of the real money supply. Dividends are average real dividends over the most recent four quarters. Panel A includes both stock market volatility and REIT volatility as measures of risk. Panel B includes REIT volatility as risk measure and in Panel $\mathrm{C}$ volatility is measured by stock market volatility. ( $t$-statistics in parentheses.)

\begin{tabular}{|c|c|c|c|c|c|c|c|c|}
\hline \multicolumn{2}{|c|}{ Dividends } & \multicolumn{2}{|c|}{ Interest Rates } & \multicolumn{2}{|c|}{ Volatility } & \multirow{2}{*}{$\begin{array}{l}\text { Industrial } \\
\text { Production }\end{array}$} & \multirow{2}{*}{$\begin{array}{l}\text { Real } \\
\text { Money }\end{array}$} & \multirow[b]{2}{*}{$\overline{R^{2}}$} \\
\hline Property & REIT & Long & Short & Stock & REIT & & & \\
\hline \multicolumn{9}{|c|}{ Panel A } \\
\hline \multirow[t]{2}{*}{$\begin{array}{l}0.487 \\
(2.787)^{* * *}\end{array}$} & & $\begin{array}{l}0.128 \\
(0.318)\end{array}$ & $\begin{array}{l}-0.153 \\
(-0.746)\end{array}$ & $\begin{array}{l}-0.004 \\
(-0.964)\end{array}$ & $\begin{array}{l}0.002 \\
(0.472)\end{array}$ & $\begin{array}{l}0.307 \\
(1.979)^{* *}\end{array}$ & $\begin{array}{l}-0.190 \\
(-1.565)\end{array}$ & 0.082 \\
\hline & $\begin{array}{l}0.111 \\
(2.104)^{* *}\end{array}$ & $\begin{array}{l}-0.061 \\
(-0.152)\end{array}$ & $\begin{array}{l}-0.187 \\
(-0.889)\end{array}$ & $\begin{array}{l}-0.004 \\
(-0.879)\end{array}$ & $\begin{array}{l}0.002 \\
(0.496)\end{array}$ & $\begin{array}{l}0.328 \\
(2.078)^{* *}\end{array}$ & $\begin{array}{l}-0.141 \\
(-1.127)\end{array}$ & 0.052 \\
\hline $\begin{array}{l}0.397 \\
(2.196)^{* *}\end{array}$ & $\begin{array}{l}0.097 \\
(1.826)^{*}\end{array}$ & $\begin{array}{l}0.172 \\
(0.419)\end{array}$ & $\begin{array}{l}-0.220 \\
(-1.058)\end{array}$ & $\begin{array}{l}-0.004 \\
(-0.862)\end{array}$ & $\begin{array}{l}0.002 \\
(0.511)\end{array}$ & $\begin{array}{l}0.242 \\
(1.495)\end{array}$ & $\begin{array}{l}-0.197 \\
(-1.578)\end{array}$ & 0.078 \\
\hline \multicolumn{9}{|c|}{ Panel B } \\
\hline \multirow[t]{2}{*}{$\begin{array}{l}0.511 \\
(2.929)^{* * *}\end{array}$} & & $\begin{array}{l}-0.070 \\
(-0.179)\end{array}$ & $\begin{array}{l}-0.009 \\
(-0.046)\end{array}$ & & $\begin{array}{l}0.000 \\
(0.000)\end{array}$ & $\begin{array}{l}0.234 \\
(1.534)\end{array}$ & $\begin{array}{l}-0.212 \\
(-1.754)^{*}\end{array}$ & 0.083 \\
\hline & $\begin{array}{l}0.113 \\
(2.153)^{* * *}\end{array}$ & $\begin{array}{l}-0.260 \\
(-0.661)\end{array}$ & $\begin{array}{l}-0.043 \\
(-0.214)\end{array}$ & & $\begin{array}{l}0.000 \\
(0.000)\end{array}$ & $\begin{array}{l}0.254 \\
(1.638)^{*}\end{array}$ & $\begin{array}{l}-0.165 \\
(-1.328)\end{array}$ & 0.050 \\
\hline $\begin{array}{l}0.406 \\
(2.249)^{* *}\end{array}$ & $\begin{array}{l}0.101 \\
(1.908)^{*}\end{array}$ & $\begin{array}{l}0.012 \\
(0.029)\end{array}$ & $\begin{array}{l}-0.098 \\
(-0.487)\end{array}$ & & $\begin{array}{l}0.000 \\
(0.000)\end{array}$ & $\begin{array}{l}0.161 \\
(1.016)\end{array}$ & $\begin{array}{l}-0.225 \\
(-1.811)^{*}\end{array}$ & 0.080 \\
\hline \multicolumn{9}{|c|}{ Panel C } \\
\hline $\begin{array}{l}0.496 \\
(2.857)^{* * *}\end{array}$ & & $\begin{array}{l}0.103 \\
(0.261)\end{array}$ & $\begin{array}{l}-0.118 \\
(-0.582)\end{array}$ & $\begin{array}{l}-0.003 \\
(-1.081)\end{array}$ & & $\begin{array}{l}0.270 \\
(1.774)^{*}\end{array}$ & $\begin{array}{l}-0.226 \\
(-1.926)^{*}\end{array}$ & 0.092 \\
\hline & $\begin{array}{l}0.110 \\
(2.109)^{* *}\end{array}$ & $\begin{array}{l}-0.070 \\
(-0.177)\end{array}$ & $\begin{array}{l}-0.163 \\
(-0.782)\end{array}$ & $\begin{array}{l}-0.002 \\
(-0.873)\end{array}$ & & $\begin{array}{l}0.280 \\
(1.837)^{*}\end{array}$ & $\begin{array}{l}-0.181 \\
(-1.510)\end{array}$ & 0.060 \\
\hline $\begin{array}{l}0.402 \\
(2.235)^{* *}\end{array}$ & $\begin{array}{l}0.095 \\
(1.804)^{*}\end{array}$ & $\begin{array}{l}0.155 \\
(0.386)\end{array}$ & $\begin{array}{l}-0.190 \\
(-0.923)\end{array}$ & $\begin{array}{l}-0.002 \\
(-0.866)\end{array}$ & & $\begin{array}{l}0.200 \\
(1.264)\end{array}$ & $\begin{array}{l}-0.238 \\
(-1.970)^{* *}\end{array}$ & 0.089 \\
\hline
\end{tabular}

${ }^{*}: p<10 \%{ }^{* *}: p<5 \%{ }^{* * *}: p<1 \%$. 
Table 4: REIT Returns

The dependent variable is the real return on a portfolio of Real Estate Investment Trusts (REITs). Reported estimates correspond to the regression of real returns on innovations in predictive variables. Innovations are from a VAR system that includes all predictive variables, time trend, and quarterly dummies. Predictive variables are the logarithm of real dividends (both for directly owned properties and for REITs), long-term and short-term interest rates, the logarithm of volatility, the logarithm of industrial production, and the logarithm of the real money supply. Panel A includes both stock market volatility and REIT volatility as measures of risk. Panel B includes REIT volatility as risk measure and in Panel C risk is measured by stock market volatility. ( $t$-statistics in parentheses.)

\begin{tabular}{|c|c|c|c|c|c|c|c|c|}
\hline \multicolumn{2}{|c|}{ Dividends } & \multicolumn{2}{|c|}{ Interest Rates } & \multicolumn{2}{|c|}{ Volatility } & \multirow{2}{*}{$\begin{array}{l}\text { Industrial } \\
\text { Production }\end{array}$} & \multirow{2}{*}{$\begin{array}{l}\text { Real } \\
\text { Money }\end{array}$} & \multirow[b]{2}{*}{$\overline{R^{2}}$} \\
\hline Property & REIT & Long & Short & Stock & REIT & & & \\
\hline \multicolumn{9}{|c|}{ Panel A } \\
\hline \multirow{4}{*}{$\begin{array}{l}0.204 \\
(0.656)\end{array}$} & & 0.437 & -0.926 & -0.037 & -0.030 & -0.947 & -1.054 & 0.147 \\
\hline & & $(0.232)$ & $(-0.963)$ & $(-1.826)^{*}$ & $(-1.498)$ & $(-1.316)$ & $(-1.884)^{*}$ & \\
\hline & 0.147 & 0.319 & -1.423 & -0.030 & -0.034 & -0.803 & -1.028 & 0.187 \\
\hline & $(2.580)^{* * *}$ & $(0.173)$ & $(-1.493)$ & $(-1.500)$ & $(-1.774)^{*}$ & $(-1.136)$ & $(-1.890)^{*}$ & \\
\hline 0.213 & 0.138 & 0.352 & -1.412 & -0.029 & -0.036 & -0.828 & -1.040 & 0.238 \\
\hline$(0.663)$ & $(2.240)^{* * *}$ & $(0.190)$ & $(-1.477)$ & $(-1.420)$ & $(-1.848)^{*}$ & $(-1.157)$ & $(-1.898)^{*}$ & \\
\hline \multicolumn{9}{|c|}{ Panel B } \\
\hline 0.277 & & -0.034 & -0.860 & & -0.058 & -0.981 & -1.108 & 0.135 \\
\hline \multirow[t]{3}{*}{$(0.890)$} & & $(-0.018)$ & $(-0.918)$ & & $(-4.363)^{* * *}$ & $(-1.369)$ & $(-1.977)^{* *}$ & \\
\hline & 0.161 & -0.159 & -1.344 & & -0.056 & -0.845 & -1.084 & 0.183 \\
\hline & $(2.864)^{* * *}$ & $(-0.089)$ & $(-1.457)$ & & $(-4.452)^{* * *}$ & $(-1.208)$ & $(-1.999)^{* *}$ & \\
\hline 0.260 & 0.151 & -0.098 & -1.328 & & -0.057 & -0.883 & -1.092 & 0.180 \\
\hline$(0.815)$ & $(2.468)^{* * *}$ & $(-0.054)$ & $(-1.437)$ & & $(-4.431)^{* * *}$ & $(-1.250)$ & $(-2.001)^{* *}$ & \\
\hline \multicolumn{9}{|c|}{ Panel C } \\
\hline 0.108 & & 0.858 & -1.122 & -0.059 & & -0.730 & -0.847 & 0.132 \\
\hline \multirow[t]{3}{*}{$(0.351)$} & & $(0.457)$ & $(-1.165)$ & $(-4.310)^{* * *}$ & & $(-1.024)$ & $(-1.542)$ & \\
\hline & 0.127 & 0.834 & -1.600 & -0.056 & & -0.561 & -0.829 & 0.166 \\
\hline & $(2.238)^{* *}$ & $(0.453)$ & $(-1.669)^{*}$ & $(-4.221)^{* * *}$ & & $(-0.803)$ & $(-1.542)$ & \\
\hline 0.107 & 0.128 & 0.863 & -1.592 & -0.056 & & -0.602 & -0.822 & 0.160 \\
\hline$(0.334)$ & $(2.055)^{* *}$ & $(0.466)$ & $(-1.654)^{*}$ & $(-4.112)^{* * *}$ & & $(-0.845)$ & $(-1.521)$ & \\
\hline
\end{tabular}

${ }^{*}: p<10 \%{ }^{* *}: p<5 \%$; ${ }^{* *}: p<1 \%$. 
Table 5: OLS Regressions of Two Types of Yield on the Risk-Free Rate.

This table shows results from two OLS regressions which model changes in two types of dividend yield on changes in the risk-free rate. In Model 1 the dependent variable is the first difference of the natural logarithm in the Dividend Yield (defined as the ratio of the weighted average quarterly dividend per share to the REIT portfolio, over end-of-quarter weighted average share price price of the REIT portfolio). In Model 2, the dependent variable is the first difference in the natural logarithm of the NOI Yield (defined as the ratio of the weighted average quarterly total Net Operating Income (NOI) per square foot to the NCREIF property portfolio, over the weighted average share price of the REIT portfolio). In both models, the independent variable is the quarterly change in the natural logarithm of the long-term interest rate. (T-statistics in parentheses).

\begin{tabular}{lcc}
\hline \hline & Model 1: $\Delta$ div.yield & Model 2: $\Delta$ noi.yield \\
\hline (Intercept) & -0.0104 & 0.0015 \\
& $(-0.3567)$ & $(0.1510)$ \\
$\Delta$ lt.rate & -0.5101 & 0.2393 \\
& $(-1.2537)$ & $(1.7307)^{\circ}$ \\
\hline$R^{2}$ & 0.01435 & 0.02698 \\
$F$ & 1.572 & $2.995^{\circ}$ \\
$N$ & 110 & 110 \\
\hline \hline
\end{tabular}

${ }^{\circ}: p<10 \%{ }^{*}: p<5 \%{ }^{* *}: p<1 \%{ }^{* * *}: p<0.1 \%$. 
Table 6: Matrix of Results from First-Order Vector Autoregression

This table presents coefficient estimates from a first-order Vector Autoregression (VAR). The system consist of the natural logarithm of the dividend yield to the value-weighted REIT portfolio (div.yield), the quarterly dividend growth rate to this portfolio ( $\Delta$ dividend), the NOI Yield, defined as the ratio of the quarterly Net Operating Income (NOI) to the direct property portfolio over the weighted average price of the REIT portfolio, the quarterly NOI growth rate for the direct property portfolio $(\Delta n o i)$, and the long-term interest rate (lt.rate). All variables are computed as the natural logarithm of their respective raw series, and all change variables are computed as the first difference of the natural logarithms. A time trend variable is included in the VAR system. All variables are de-meaned. The F-statistic included is the joint significance test that all variables are different from zero, for each equation of the system. (T-statistics in parentheses).

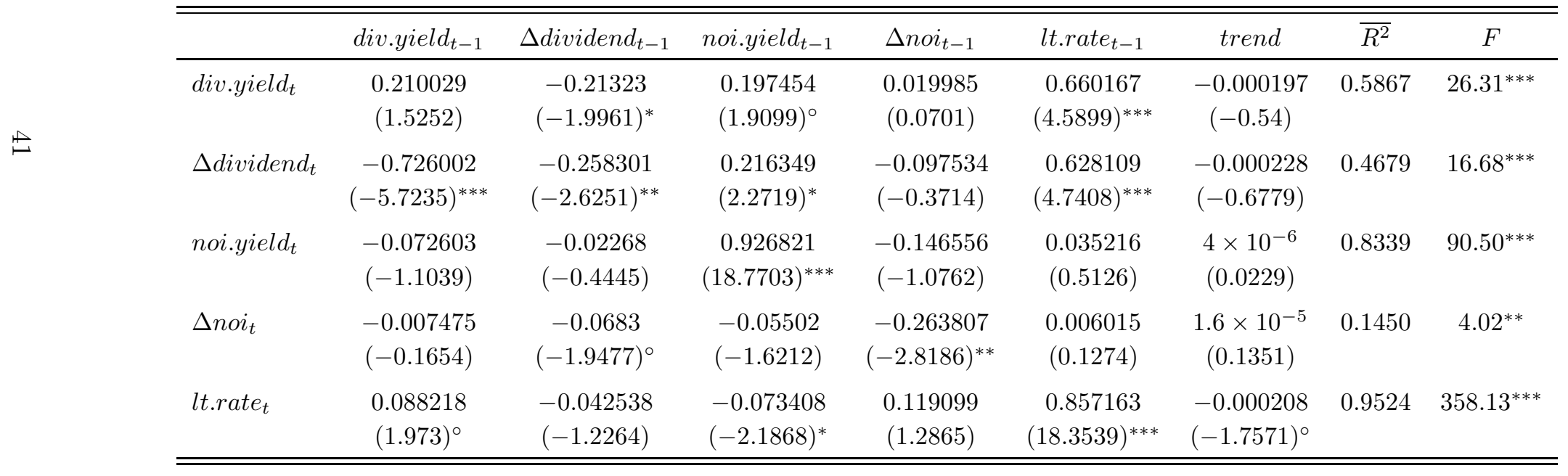

Number of observations: 108

${ }^{\circ}: p<10 \% ;{ }^{*}: p<5 \%{ }^{* *}: p<1 \%{ }^{* * *}: p<0.1 \%$. 
Table 7: Results from Rolling Vector Autoregressions.

This table presents statistics comparing of the predicted dividend yield for quarter $t+1$ (generated by a VAR using 40 quarters' worth of data, ending at $t$ ), with the ex-post realized pred.div.yield $d_{t, t+1}$ dividend yield at quarter $t$, div.yield $d_{t+1}$. Specifically, the table presents, for each VAR specification the ratio of the standard deviations between the predicted and the realized series, as well as their correlation coefficient. In parentheses there is the value of a t-statistic testing the hypothesis that the actual

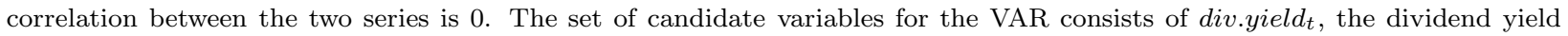
to the value-weighted REIT portfolio, $\Delta$ dividend $_{t}$, the quarterly growth in the weighted-average REIT dividend, noi.yield the ratio of the quarterly weighted-average net operating income (NOI) per square foot to the property portfolio, over the weighted-average end-of-quarter price to the REIT portfolio, $\Delta$ noi $_{t}$ the quarterly NOI growth, and lt.rate $e_{t}$, the long-term interest rate. All variables are computed as the natural logarithm of their respective raw series, and all change variables are computed as the first difference of the natural logarithms. All variables are de-meaned.

\begin{tabular}{|c|c|c|}
\hline \multicolumn{3}{|c|}{ VAR System 1: $\left.\left[\text { div.yield }_{t}, \Delta \text { dividend }_{t} \text {, lt.rate }\right]_{t}\right]^{\prime}$} \\
\hline Lags: & 1 & 2 \\
\hline$\sigma\left(\right.$ pred.div.yield $\left.d_{t, t+1}\right) / \sigma\left(\right.$ div.yield $\left.d_{t+1}\right)$ & 0.6941 & 0.7108 \\
\hline $\operatorname{cor}\left(\right.$ pred.div.yield $t_{t, t+1}$, div.yield $\left.d_{t+1}\right)$ & $\begin{array}{c}0.4593 \\
(4.201)^{* * *}\end{array}$ & $\begin{array}{c}0.4528 \\
(4.126)^{* * *}\end{array}$ \\
\hline \multicolumn{3}{|c|}{ VAR System 2: $\left[\text { div.yield }_{t}, \Delta \text { dividend }_{t}, \text { noi.yield }_{t}, \text { lt.rate }_{t}\right]^{\prime}$} \\
\hline Lags: & 1 & 2 \\
\hline$\sigma\left(\right.$ pred.div.yield $\left.d_{t, t+1}\right) / \sigma\left(\right.$ div.yield $\left.d_{t+1}\right)$ & 0.9298 & 0.9563 \\
\hline $\operatorname{cor}\left(\right.$ pred.div.yield $d_{t, t+1}$, div.yield $\left.d_{t+1}\right)$ & $\begin{array}{c}0.6086 \\
(6.232)^{* * *} \\
\end{array}$ & $\begin{array}{c}0.6847 \\
(7.631)^{* * *} \\
\end{array}$ \\
\hline \multicolumn{3}{|c|}{ VAR System 3: $\left[\right.$ div.yield $_{t}, \Delta$ dividend $_{t}$, noi.yield $_{t}, \Delta$ noi $_{t}$, lt.rate ${ }_{t}$} \\
\hline Lags: & 1 & 2 \\
\hline$\sigma\left(\right.$ pred.div.yield $\left.d_{t, t+1}\right) / \sigma\left(\right.$ div.yield $\left.{ }_{t+1}\right)$ & 0.9765 & 0.9813 \\
\hline $\operatorname{cor}\left(\right.$ pred.div.yield $d_{t, t+1}$, div.yield $\left.d_{t+1}\right)$ & $\begin{array}{c}0.6503 \\
(6.955)^{* * *} \\
\end{array}$ & $\begin{array}{c}0.7323 \\
(8.736)^{* * *} \\
\end{array}$ \\
\hline \multicolumn{3}{|c|}{ VAR System 4: $\left[\text { div.yield }_{t}, \text { noi.yield } d_{t}, \Delta \text { noi }_{t}, \text { lt.rate }_{t}\right]^{\prime}$} \\
\hline Lags: & 1 & 2 \\
\hline$\sigma\left(\right.$ pred.div.yield $\left.{ }_{t, t+1}\right) / \sigma\left(\right.$ div.yield $\left._{t+1}\right)$ & 0.9464 & 0.9291 \\
\hline $\operatorname{cor}\left(\right.$ pred.div.yield $d_{t, t+1}$, div.yield $\left.d_{t+1}\right)$ & $\begin{array}{c}0.5949 \\
(6.012)^{* * *}\end{array}$ & $\begin{array}{c}0.7313 \\
(8.712)^{* * *}\end{array}$ \\
\hline
\end{tabular}

VARs are computed on a rolling 40-quarter window. Statistics are computed on the remaining 68 observations.

${ }^{\circ}: p<10 \%{ }^{*}: p<5 \%{ }^{* *}: p<1 \%{ }^{* * *}: p<0.1 \%$. 


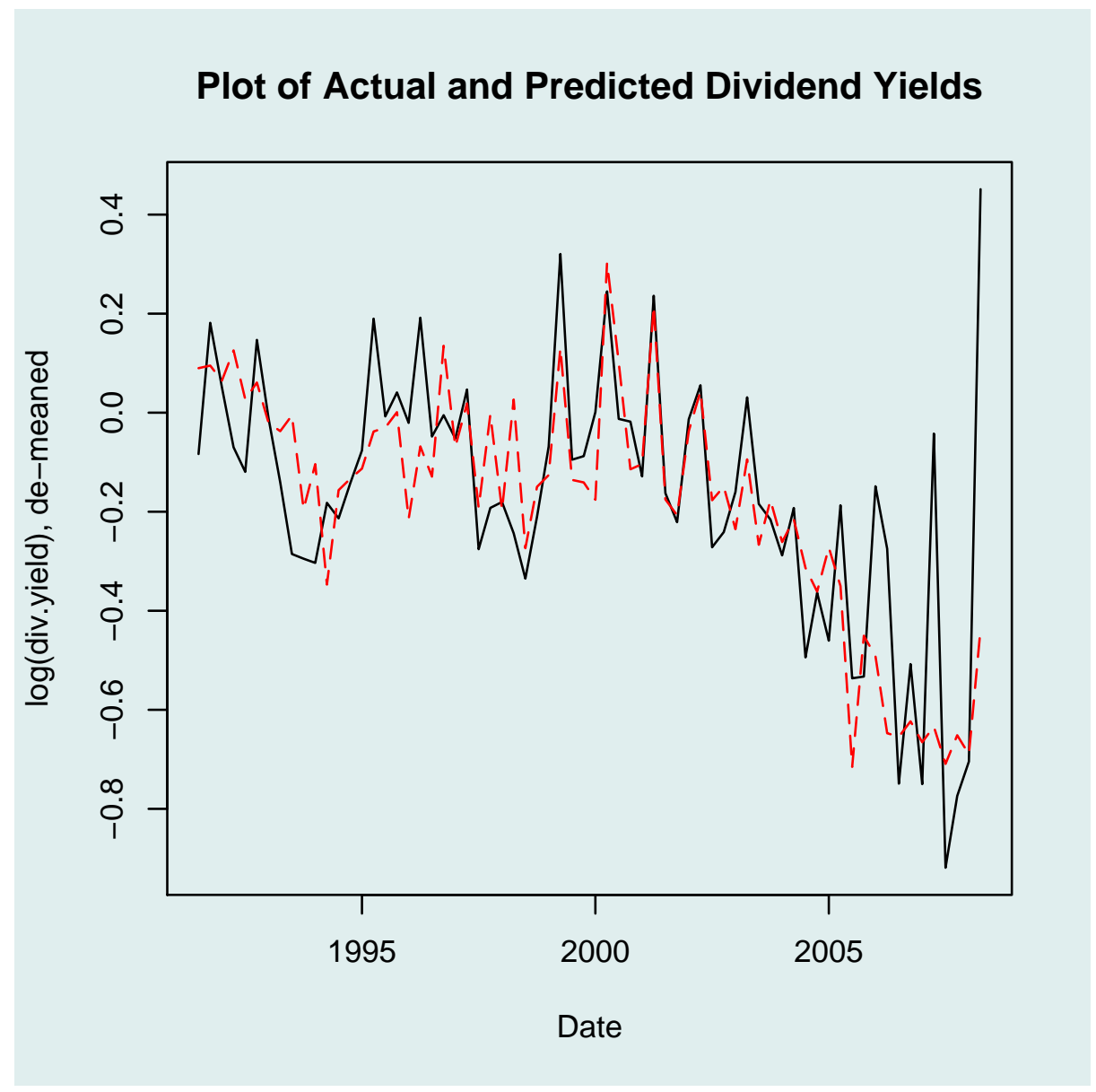

Figure 1: This figure shows a plot of the log of realized dividend yields (the black continuous line) and predicted dividend yields from VAR System 4 (Table 7) for the same quarter (the red dashed line). 
Table 8: Regression Results of Residual Dividend Yield on Realized Quarterly REIT Volatility.

This table presents results from an OLS regression of the difference between ex-post realized dividend yield on the REIT portfolio (div.yield $t+1)$ minus the predicted dividend yields, generated through a 40-quarter rolling window VAR in quarter $t$, and concerning quarter $t+1$. Each of the variables pred.div.yield $t, t+1, i$ corresponds to the predicted dividend yields generated by VAR system $i$ in table 7 . The independent variable is the logarithm of the volatility of daily returns on the value-weighted REIT portfolio for quarter $t+1$, minus its mean. (T-statistics in parentheses).

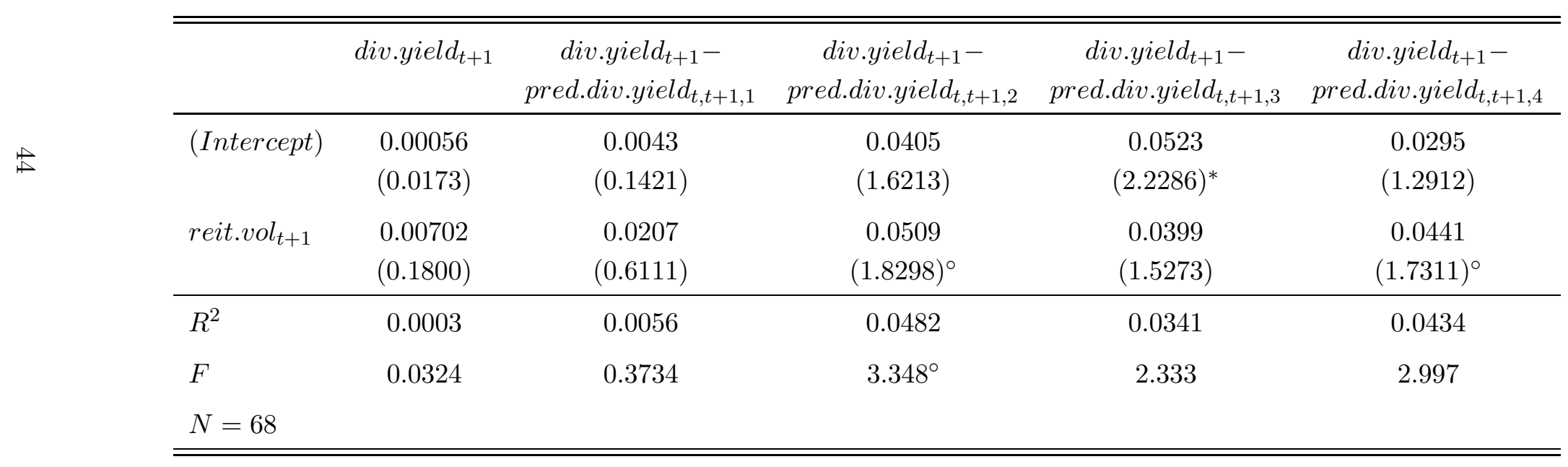

${ }^{\circ}: p<10 \%{ }^{*}: p<5 \%{ }^{* *}: p<1 \%{ }^{* * *}: p<0.1 \%$. 